Research Article

\title{
Influence of Existing Defects on Mechanical Properties of NC Lining
}

\author{
Sen Zhang $\mathbb{D}^{1,2}$ Zhihua Ren, ${ }^{1}$ Zude Ding $\mathbb{D}^{3},{ }^{3}$ Jincheng Wen, ${ }^{3}$ and Zhixin Yan $\mathbb{D}^{2,4}$ \\ ${ }^{1}$ Yunnan Research Institute of Highway Science and Technology, Kunming 650051, China \\ ${ }^{2}$ College of Civil Engineering and Mechanics, Lanzhou University, Lanzhou, Gansu 730000, China \\ ${ }^{3}$ Faculty of Civil Engineering and Mechanics, Kunming University of Science and Technology, Kunming 650500, China \\ ${ }^{4}$ School of Civil and Transportation Engineering, Henan University of Urban Construction, Pingdingshan 467036, China \\ Correspondence should be addressed to Zude Ding; dzdvsdt@163.com
}

Received 20 April 2019; Revised 25 October 2019; Accepted 2 November 2019; Published 19 December 2019

Academic Editor: Davide Palumbo

Copyright (C) 2019 Sen Zhang et al. This is an open access article distributed under the Creative Commons Attribution License, which permits unrestricted use, distribution, and reproduction in any medium, provided the original work is properly cited.

\begin{abstract}
The mechanical properties of the lining are directly affected by defects such as voids behind the lining and insufficient thickness of the lining. In order to quantitatively evaluate this effect, the mechanical behavior of the lining under the influence of the void behind the lining, the insufficient thickness of the lining, and the combination of the two kinds of defects are adopted by the $1 / 5$ scale model test. Based on the experimental research, numerical calculation models based on the CDP model for defect lining are established, with the effects of load direction, stratum stiffness, defect location, defect type, and degree on the mechanical behavior of the lining analyzed by the numerical simulation. The experimental and numerical results show that the void weakens the stiffness of the lining. As the void range increases, the lining becomes more deformable and its bearing capacity decreases with the " $\mathrm{S}$ " curve. Thinning significantly reduces the deformation properties of the lining and the bearing capacity and stiffness of the thinned section. The lining bearing capacity decreases linearly with the increase of the thinning ratio, when the load is applied at the thinning. With the influence of combined defects on the load-displacement curve of the lining fluctuating drastically, the mechanical properties of the lining are significantly reduced. The bearing capacity of lining decreases with the increase of composite defects in a "S" shape. The effect of void and lining thinning on the lining bearing capacity increases with the increase of the stiffness of the formation. The loss rate equation of the concrete lining bearing capacity under the influence of existing defects is established by using the L-M nonlinear regression analysis, a provision of scientific guidance for the safety evaluation of the defect lining.
\end{abstract}

\section{Introduction}

Because of the complex environment, unclear load characteristics, and construction quality problems, lining cracking, leakage, and other problems become common and are difficult to prevent and treat [1-3]. Among them, voids behind the lining and insufficient thickness of the lining are two common tunnel quality defects caused by inappropriate construction, which are one of the main causes of tunnel damage $[4,5]$ and have a serious impact on the safety and durability of the structure [6].

At present, some research work has been carried out on the influence of existing defects, such as voids behind the lining and insufficient thickness, by means of statistics, theoretical analysis, numerical calculation, and laboratory tests, from which a lot of achievements have been gained [7-15]. It is found that voids behind the lining will cause stress redistribution of surrounding rock and then change the stress state of lining $[7,8]$. The influence of different positions of voids on the stress state, failure mode, and safety factor of the lining structure varies [9]. It is noteworthy that the crown has the greatest influence on the structural safety factor [10], and the crown is also the most prone part to form voids [10]. The test results show that with the increase of the void range, the stress concentration of the lining becomes more serious, the axial force of the lining structure decreases as a whole, and the bending moment of the lining within the void range and between the voids increases obviously, which 
leads to the deterioration of the stress state and the decrease of the structural safety $[11,12]$. Insufficient thickness of the lining will directly reduce the bearing capacity and stiffness of the lining section in this part; on the other hand, it may reduce the contact stress between the supporting structure and surrounding rock, reduce the bearing capacity and stiffness of the lining, and deteriorate the stress state of the structure [13]. Under different load conditions, the lining with insufficient thickness will have different degrees of deformation and failure modes, and the order of damage will change accordingly [14]. In addition, the worse the surrounding rock is, the higher the sensitivity to lining thinning is and the greater the harm caused by lining thinning. During practice in tunnels, it is found that the insufficient thickness of the lining often occurs with the formation of voids behind the lining, and the mechanical properties of the lining under the defect combination are different from those under the single defect [15].

However, most of the existing studies have qualitatively evaluated the influence of defects on tunnel lining structure from internal force distribution of the lining and structural safety analysis $[16,17]$, but the quantitative evaluation about the decline of lining bearing capacity under the influence of defects is insufficient. Moreover, the existing experimental and computational studies mostly focus on the single defect, and there is little research on the bearing capacity of lining under the influence of the combination of two defects [14]. In addition, the small-scale model test $[8,15,18]$ has been used in the existing experimental studies, which makes it difficult to solve the problem of material similarity. Therefore, this paper uses the $1 / 5$ scale lining model test and numerical simulation method to study the mechanical behavior of lining under voids behind the lining, insufficient thickness of the lining, and the combination of two kinds of defects. On the basis of laboratory test and numerical calculation, the mathematical equation of the influence of existing defects on the bearing capacity of lining is established, which provides scientific basis for quantitative evaluation of the influence of defects on the mechanical properties of lining and treatment design.

\section{Experimental Plan}

2.1. Layout of Testing Device and Sensor. In order to carry out the model test of the stress performance of the lining under the influence of defects, a horizontal loading test device for lining is developed [19]. Figure 1 shows the loading device and sensor arrangement under the vertical loading condition. The model device is $3,950 \mathrm{~mm}$ wide and $2,610 \mathrm{~mm}$ high, including a reaction steel frame, electrohydraulic jack, and formation restraint device. 9 loading positions are set around the lining internally. Through the installation of the $300 \mathrm{kN}$ electrohydraulic jack at each loading position, the loading at any position can be realized. Unloaded parts simulate formation reaction through the combination of the rubber plate and jack. Taking the vertical loading of crown as an example, the layout of model test elements is shown in Figure 1(b). 9 displacement measuring positions are arranged inside the lining and measured by displacement transducer; 30 strain gauges are symmetrically arranged inside and outside the lining to measure the strain inside and outside; and pressure sensors are arranged at the position of the lining crown to measure the vertical load.

2.2. Test Materials and Specimens. In this paper, the geometric similarity ratio of model test is $1 / 5$, and the prototype material is used for model test. The model lining is made of C25 concrete. The compressive strength of concrete is 28.2 $\mathrm{MPa}$ measured by the standard cube compressive strength test. Taking the common two-lane highway tunnel lining in China as the prototype, the model lining specimens are made according to $1 / 5$ scale. The lining specimens are $2.3 \mathrm{~m}$ wide, $1.56 \mathrm{~m}$ high, $80 \mathrm{~mm}$ thick, and $300 \mathrm{~mm}$ long. Based on the existing achievements [20,21], eight $10 \mathrm{~cm}$ thick elastic rubber plates are used to simulate the formation constraints around the lining. The size of a single rubber cushion plate is $0.3 \mathrm{~m} \times 0.3 \mathrm{~m}$. The side of the rubber plate in contact with the lining is processed into an arc so that it can be closely adhered to the lining. The elastic coefficient of the rubber plate is determined by the uniaxial compression test, which is $3.38 \mathrm{MN} / \mathrm{m}$. The equivalent formation resistance coefficient is $27.9 \mathrm{MPa} / \mathrm{m}$. The field test picture is shown in Figure 2.

2.3. Test Condition. The external loads causing lining failure can be categorized into vertical relaxation ground pressure, biased ground pressure, and horizontal plastic ground pressure [20, 22]. For simplicity, this test only considers vertical and oblique load directions to simulate lining under vertical relaxation ground pressure and biased pressure. As shown in Figure 3, aiming at the defect at crown and spandrel, the influence of voids behind the lining and insufficient thickness of lining on the mechanical properties of lining is studied. Figure 3(a) describes the 45-degree oblique loading with crown voids of the lining and insufficient thickness of the lining; Figure 3(b) describes the vertical loading with vault voids of the lining and insufficient thickness of the lining. Among them, the void range is represented by $\alpha$ angle and the insufficient thickness of the lining by the thinning ratio $\delta$. The expression is as follows:

$$
\delta=\frac{H_{0}-H_{1}}{H_{0}} \times 100 \%,
$$

where $H_{0}$ and $H_{1}$ represent the thickness of the lining before and after thinning, respectively.

In this model test, the void sizes are selected as $\alpha=30^{\circ}$ and $\alpha=60^{\circ}$, and the thinning ratios are chosen as $\delta=25 \%$ and $\delta=50 \%$, respectively. Among them, 6 working conditions are designed for the vault crown defect and 3 working conditions are designed for the spandrel defect. The vault crown void is represented by the symbol " $V$ " and its corresponding angle, and the thinning is represented by the symbol "T" and its corresponding thinning ratio. For example, V30 indicates that the void size is $30^{\circ}$, T25 indicates that the thinning ratio of lining is $25 \%$, V30T25 indicates that the void size of lining is $30^{\circ}$, and the lining is thinned by 


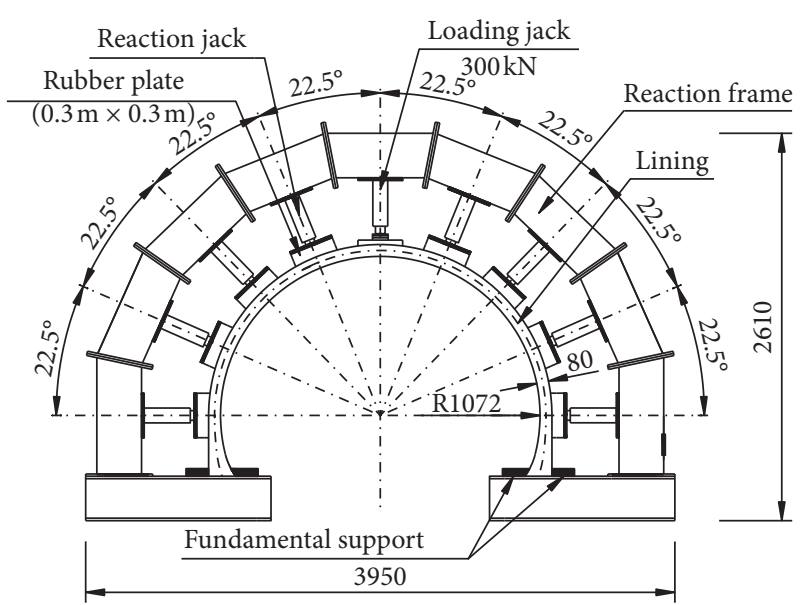

(a)

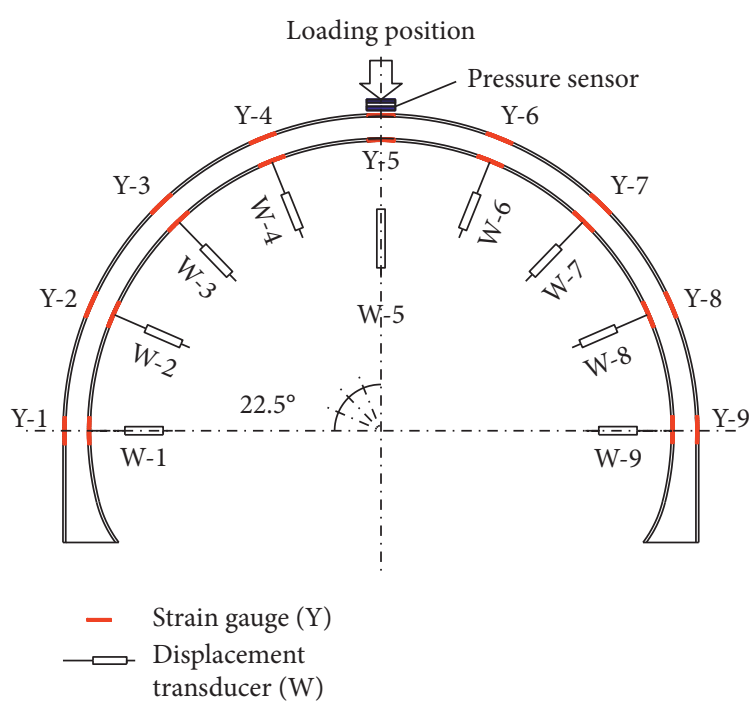

(b)

Figure 1: Diagram of layout of loading device and sensor (unit: $\mathrm{mm}$ ), (a) model device, (b) layout of testing sensor.

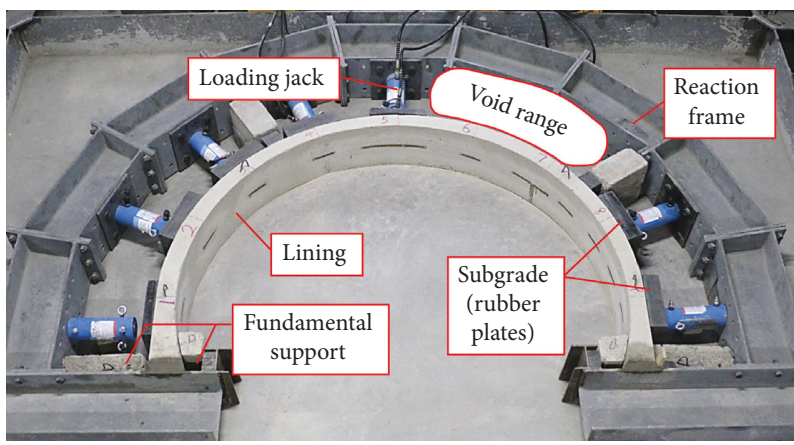

Figure 2: Field test picture.

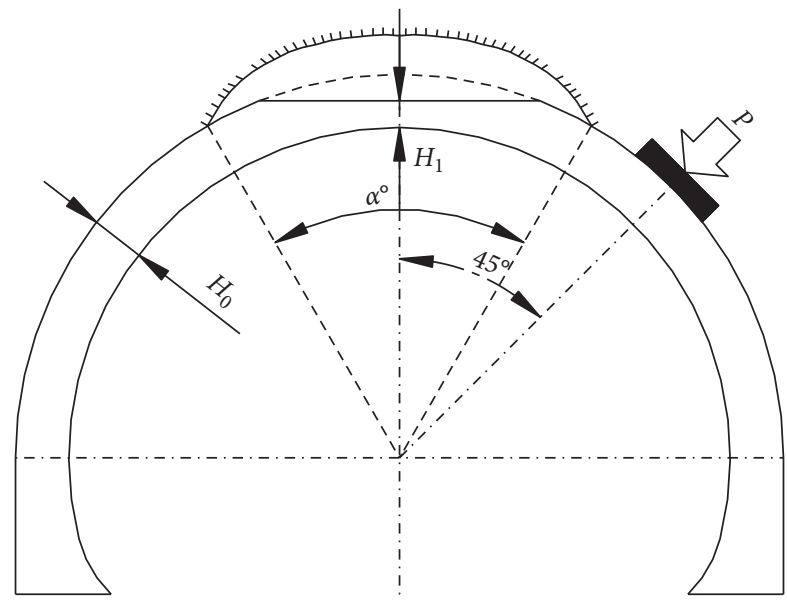

(a)

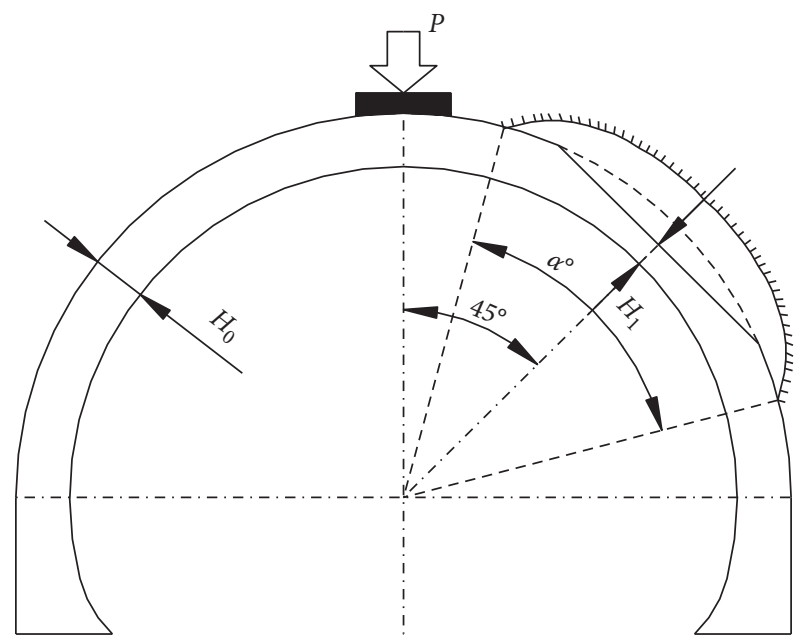

(b)

Figure 3: Diagram of set-up conditions for model test. (a) Crown void and insufficient thickness. (b) Spandrel void and insufficient thickness. 
$25 \%$. The loading rate is $0.3-0.5 \mathrm{~mm} / \mathrm{min}$. The crack width is measured, and the distribution of the cracks is recorded with every $5 \mathrm{~mm}$ increase in the displacement of the vault crown, and the loading is stopped after the lining is damaged.

\section{Analysis of Test Results}

The load-displacement curve of defective lining is shown in Figure 4, and the main results of model test are shown in Table 1. From Figure 4, it can be seen that the shape of loaddisplacement curve of lining under different defects significantly differs. When there are voids, the stiffness of the lining decreases, and the larger the void range is, the more easily the lining deforms. Under biased pressure, the thinning of the vault crown lining has little effect on the overall stiffness, but the lining shows obvious brittle failure. The influence of the combination of void and thinning defects is the greatest. The load-displacement curve of lining is not smooth with sharp zigzag. The transition of elastic, elasticplastic, and failure stages of lining under combined defects is uneven, which indicates that the mechanical properties of lining are obviously reduced.

When the vault crown void increases from $0^{\circ}$ (no voids) to $60^{\circ}$ under oblique loading, the initial crack load and its displacement decrease by $16.4 \%$ and $56.5 \%$, respectively, and the peak load and corresponding displacement decrease by $75 \%$ and $95.6 \%$, respectively. It can be seen that with the increase of the void range, the lining will crack easier, the bearing capacity will be significantly reduced, the brittleness of the lining will be increased, the deformation performance will be reduced, and the fracture or crushing failure will be more likely to occur. When the thinning ratio of vault crown lining increases from 0 (no voids) to $50 \%$, the initial crack load decreases by $25.1 \%$, and the peak load and corresponding displacement decrease by $4.4 \%$ and $35.6 \%$, respectively. The thinning of lining has great influence on the initial cracking load and the corresponding displacement of peak load, and the risk of lining cracking and the degree of brittleness increase. Because of formation restraint, the influence on the overall bearing capacity of lining is not obvious. When vault crown voids and lining thinning occur at the same time, the peak load and corresponding displacement of V60T50 are only $19.9 \%$ and $3.6 \%$ of those of intact lining, respectively. Lining only has the similar bearing capacity as ground arch structure, and its deformation capacity is basically lost.

Under vertical load, the load-displacement curve of intact lining is similar to that under oblique loading, and the bearing capacity of intact lining is about $12 \%$. When there are voids and thinning in the vault spandrel lining at the same time, the shape of load-displacement curve, peak load, and displacement variation law are similar to those of the combined defects of vault crown lining under oblique loading, but the influence is slight. Taking V60T50 as an example, its peak load and corresponding displacement are only $32 \%$ and $10.4 \%$ of those of the intact lining, respectively.

Generally speaking, when the void size reaches $60^{\circ}$, the restraint effect of surrounding rock is weak, and the bearing capacity and deformation performance of lining decrease significantly; the thinning of lining mainly affects the deformation performance of lining and the bearing capacity and stiffness of thinned section but has little effect on the overall bearing capacity of the lining; it is worth noting that, whether at the crown or spandrel, the combined defects have significant effects on the bearing capacity and deformation performance of lining.

\section{Numerical Calculation Model and Its Verification}

4.1. Material Model and Parameters. The concrete damage plasticity (CDP) model in ABAQUS is used to simulate concrete in this paper. The two main failure modes assumed by the model are tensile cracking and compressive collapse of concrete. The model was proposed by Lubline in 1989 and revised by Lee and Fenves [23] in 1998, which is that the plastic flow rule is noncorrelative flow rule and the plastic potential surface follows the Drucker-Prager hyperbolic function. The model is suitable for numerical analysis of concrete under monotonic, cyclic, and dynamic loads.

According to the fracture energy criterion of concrete, it can be seen that the stress-crushing (or cracking) strain relationship of concrete is related to the mesh size of concrete element. When the mesh size of concrete element is different in the finite element model, the stress-crushing (or cracking) strain relationship of concrete is also different. Therefore, this paper defines the plastic behavior of concrete by controlling the compressive fracture energy and tensile fracture energy of a single unit of concrete and uses the stress-crushing strain curve and stress-cracking displacement curve to define the compressive and tensile behavior of concrete, respectively. The compressive stressstrain curve of concrete is calculated in accordance with Code for Design of Concrete GB50010-2010, and the tensile stress-cracking displacement curve of concrete is calculated according to the suggested formula in reference [24]. The calculation of tensile fracture energy of concrete is based on the suggestion in CEB-FIP2010. The expression is as follows [25]:

$$
G_{\mathrm{F}}=0.073\left(f_{\mathrm{cm}}\right)^{0.18}
$$

where $G_{\mathrm{F}}$ is the tensile fracture energy of concrete in units of $\mathrm{N} / \mathrm{mm}$ and $f_{\mathrm{cm}}$ is the average value of the compressive strength of concrete in units of MPa.

The compressive fracture energy of concrete is calculated according to the suggested formula given in reference [26]:

$$
G_{\mathrm{c}}=\left(\frac{f_{\mathrm{cm}}}{f_{\mathrm{ctm}}}\right)^{2} G_{\mathrm{F}},
$$

where $G_{c}$ is the compressive fracture energy of concrete in units of $\mathrm{N} / \mathrm{mm}$ and $f_{\mathrm{ctm}}$ is the average tensile strength of concrete in units of MPa.

The calculated tensile fracture energy $G_{\mathrm{F}}$ and compressive fracture energy $G_{\mathrm{F}}$ of concrete are $0.139 \mathrm{~N} / \mathrm{mm}$ and 


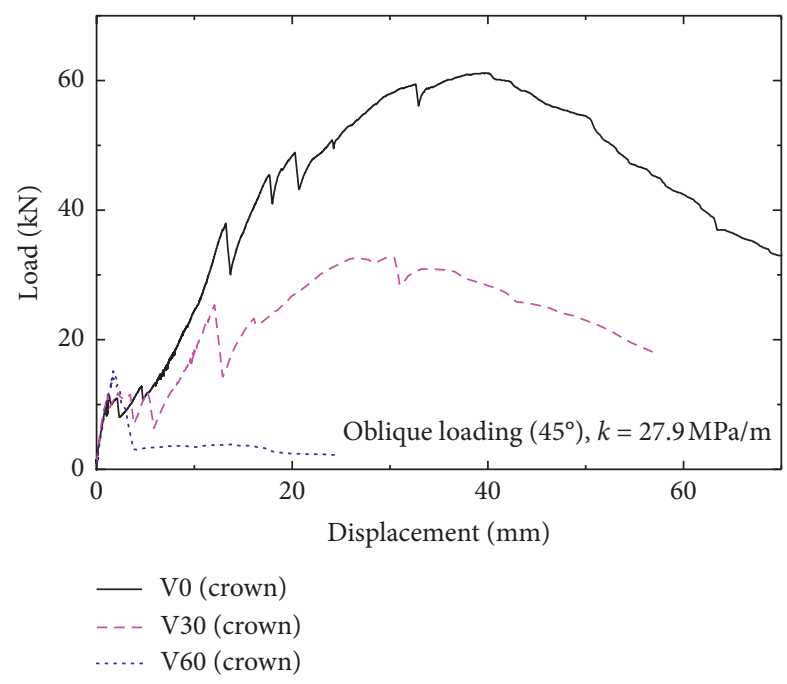

(a)

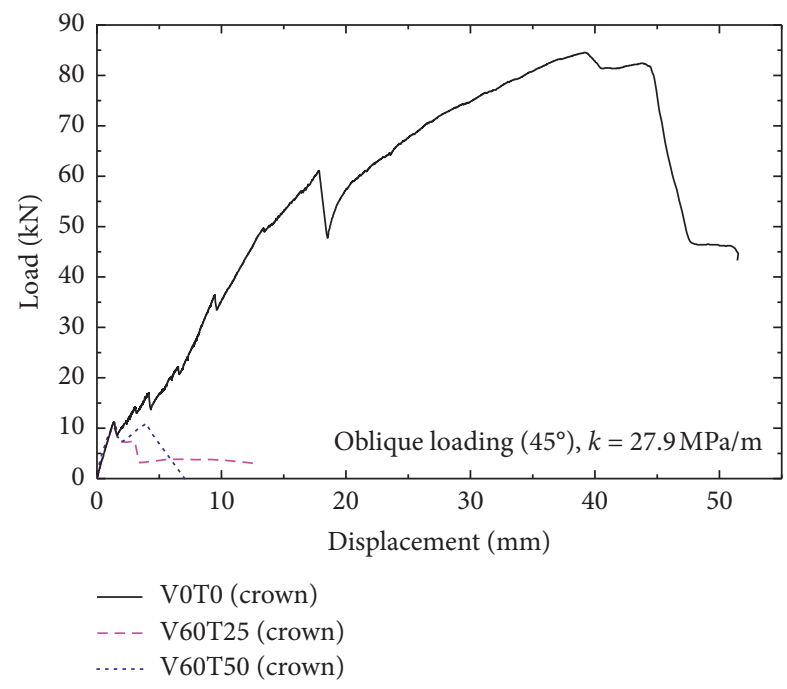

(c)

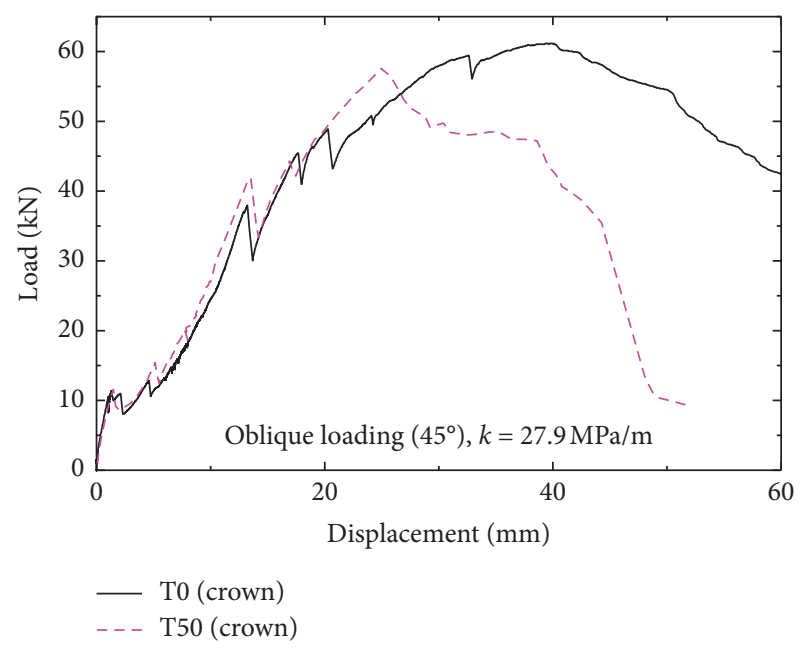

(b)

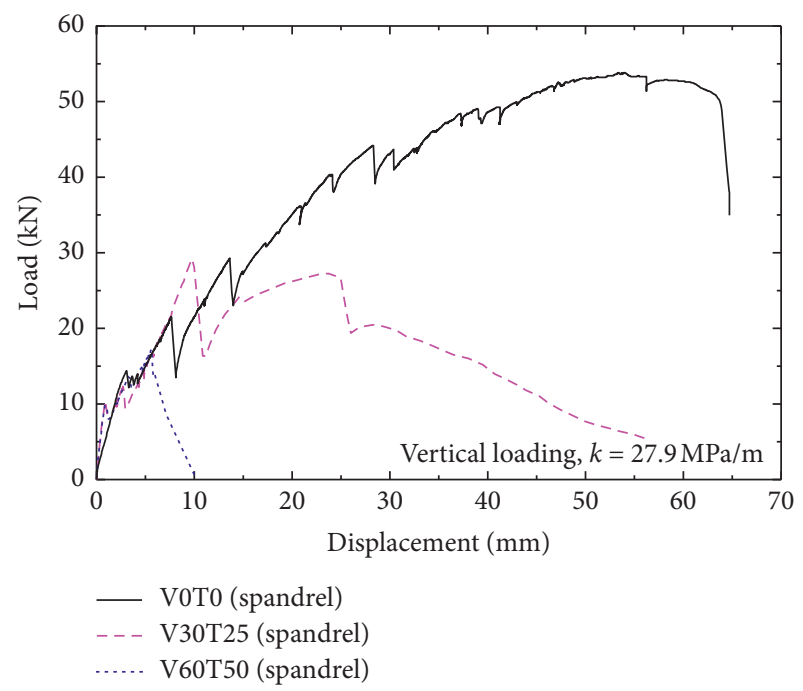

(d)

FiguRE 4: Load-displacement curve of lining defects. (a) Vault crown voids of the lining. (b) Insufficient vault crown thickness of the lining. (c) Combined vault crown defects of the lining. (d) Combined spandrel defects of the lining.

$22.57 \mathrm{~N} / \mathrm{mm}$, respectively. The relationship between compressive fracture energy and stress-strain of concrete can be expressed as follows:

$$
G_{\mathrm{c}}=l_{\mathrm{c}} \int \sigma d \varepsilon,
$$

where $l_{c}$ is the characteristic length of the unit, $l_{c}=\sqrt{2 A}$ (unit: $\mathrm{mm}$ ), and $A$ is the unit area.

When the characteristic length of the element changes, the stress-strain curve of the element will change accordingly. In this paper, a four-node plane strain element with mesh sizes of $20 \mathrm{~mm}, 10 \mathrm{~mm}$, and $5 \mathrm{~mm}$ is proposed. Destructive strain curves under three grids are obtained as shown in Figure 5(a) and the cracking displacement curves as shown in Figure 5(b).

According to Sidiroff's energy equivalence principle [27], the damage factor of the CDP model can be expressed as

$$
\begin{aligned}
& d_{\mathrm{t}}=1-\left(\frac{\sigma_{\mathrm{t}} l_{\mathrm{c}}}{E_{0} w}\right)^{0.5}, \\
& d_{\mathrm{c}}=1-\left(\frac{\sigma_{\mathrm{c}}}{E_{0} \varepsilon}\right)^{0.5}, \\
& d_{\mathrm{c}}=1-\left(\frac{\sigma_{\mathrm{c}}}{E_{0} \varepsilon_{\mathrm{c}}}\right)^{0.5}, \\
& d_{\mathrm{t}}=1-\left(\frac{\sigma_{\mathrm{t}} l_{\mathrm{c}}}{E_{0} w}\right)^{0.5},
\end{aligned}
$$

where $d_{\mathrm{t}}$ and $d_{\mathrm{c}}$ are the tensile and compressive damage factors, respectively; $\sigma_{\mathrm{t}}$ and $\sigma_{\mathrm{c}}$ are tensile and compressive stresses of concrete, respectively; $w$ is the cracking displacement of concrete; $E_{0}$ is the initial elastic modulus of 


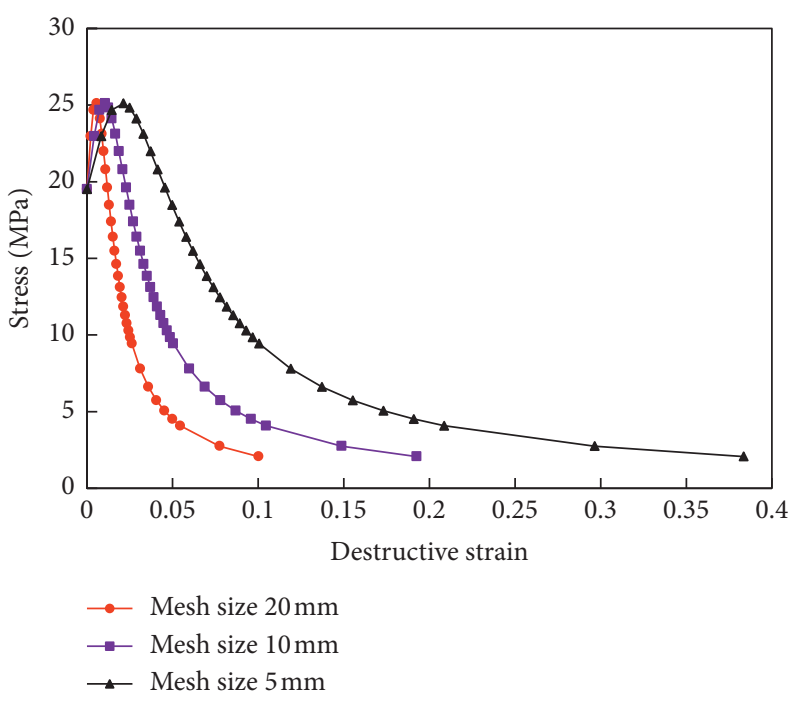

(a)

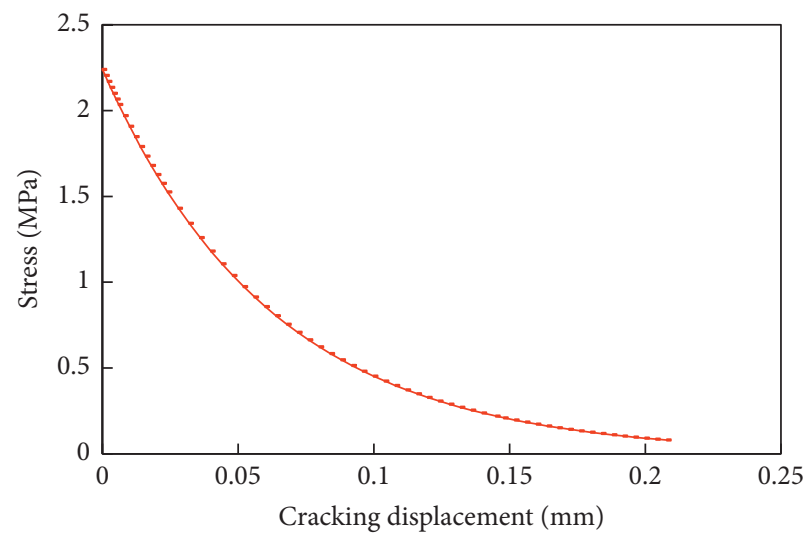

(b)

FiguRE 5: Stress-strain curve of concrete. (a) Destructive strain curve. (b) Cracking displacement curve.

TABLE 1: Values of the plastic parameters for the CDP model.

\begin{tabular}{lcccc}
\hline $\begin{array}{l}\text { Dilation angle } \\
(\psi)\end{array}$ & $\begin{array}{c}\text { Eccentricity } \\
(e)\end{array}$ & $\begin{array}{c}\text { The ratio of yield stress } f_{\mathrm{b} 0} / \\
f_{\mathrm{c} 0}\end{array}$ & $\begin{array}{c}\text { The ratio of the second stress invariant on the } \\
\text { tensile meridian }(K)\end{array}$ & $\begin{array}{c}\text { Viscosity parameter } \\
(\nu)\end{array}$ \\
\hline $30^{\circ}$ & 0.1 & 1.16 & 0.667 & $1 E-05$ \\
\hline
\end{tabular}

concrete; $\varepsilon_{\mathrm{c}}$ is compressive strain; and $l_{\mathrm{c}}$ is characteristic length of concrete integral element.

Values of the plastic parameters for the CDP model can be seen in Table 1 .

4.2. Structural Model. In this paper, ABAQUS is used to establish the lining calculation model under the above 9 test conditions. The lining is simulated by plane strain element CPE4, and the surrounding rock is simulated by spring element only under pressure. The loading and boundary conditions consistent with the model test are set. The structural calculation model is shown in Figure 6.

4.3. Validation of Numerical Simulation. The experimental and computational results of the load-displacement curve of lining under typical defects are shown in Figure 7. In the figure, "E" represents the experimental curve and "S" represents the computational curve. The figure shows that the shape of load-displacement curve is similar, and the numerical calculation curve is smoother and gentler compared with the experimental curve. The variation of bearing capacity of lining with defects is basically the same. For example, the difference between numerical results and experimental values is $9.9 \%, 4.5 \%$, and $22.6 \%$ when the void range of vault is $0^{\circ}, 30^{\circ}$, and $60^{\circ}$, respectively; for the vault combination defect V60T25 and V60T50, the difference between numerical value and experimental value is $15.3 \%$ and $10.4 \%$, respectively; for the vault spandrel combination defect V30T25 and V60T50, the difference between

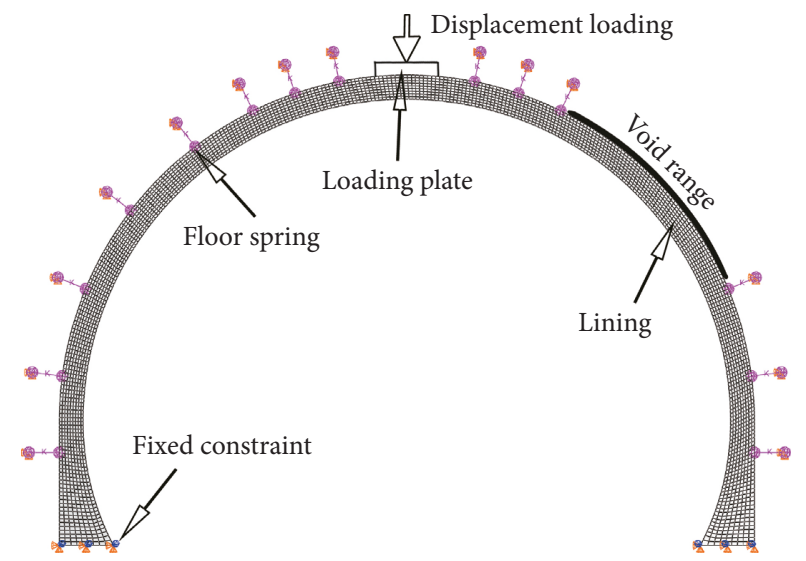

FIGURE 6: Calculation model of typical structures with defects.

numerical value and experimental value is $6.8 \%$ and $6.5 \%$, respectively. This is because the boundary conditions of the numerical simulation are idealized and the materials are homogeneous. In addition, the numerical simulation does not consider these influence factors, which can affect the calculation results, such as the friction between lining and the ground, the constitutive model selected by the numerical simulation and the size of the mesh, etc. But, the loaddisplacement curves under the two conditions are similar in shape. It can be seen that the results of numerical calculation are close to the experimental results, and the numerical model has good reliability, which can reflect the mechanical behavior of plain concrete lining under the influence of defects. 


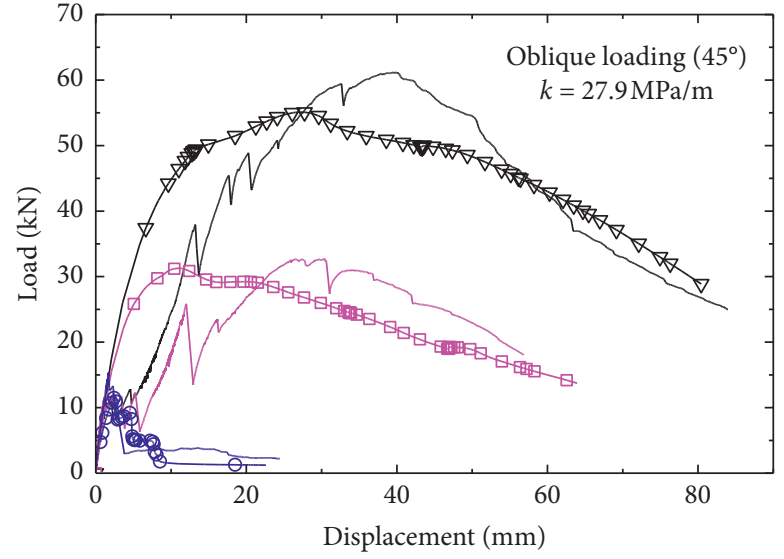

$\begin{array}{ll}-\mathrm{V} 0-\mathrm{E} \text { (crown) } & \nabla \text { V0-S (crown) } \\ -\mathrm{V} 30-\mathrm{E} \text { (crown) } & - \text { V30-S (crown) } \\ -\mathrm{V} 60-\mathrm{E} \text { (crown) } & -\mathrm{V} 60-\mathrm{S} \text { (crown) }\end{array}$

(a)

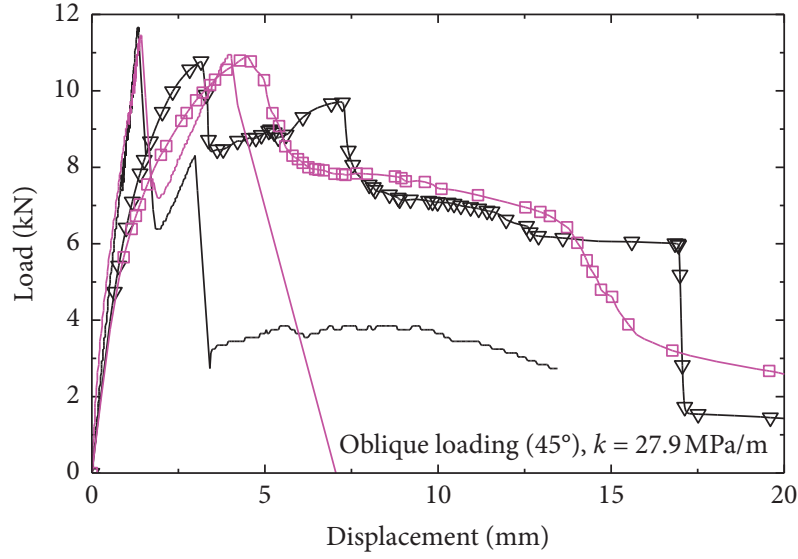

$\begin{array}{ll}\square \text { V60T25-E (crown) } & - \text { V60T50-E (crown) } \\ \square \text { V60T25-S (crown) } & \square \text { V60T50-S (crown) }\end{array}$

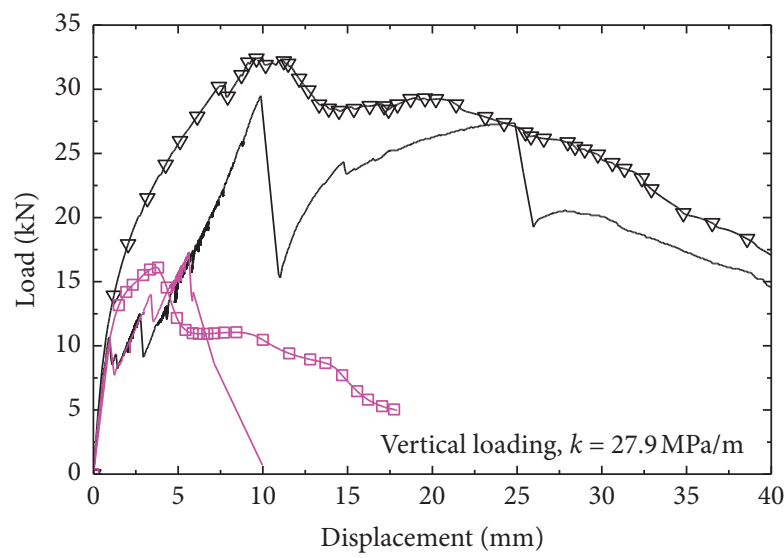

$\begin{array}{ll}- \text { V60T25-E (crown) } & - \text { V60T50-E (crown) } \\ \nabla \text { V60T25-S (crown) } & - \text { V60T50-S (crown) }\end{array}$

(c)

Figure 7: Comparative analysis of load-displacement curve of the lining. (a) Vault crown voids of the lining. (b) Combined vault crown voids of the lining. (c) Combined spandrel voids of the lining.

\section{Parameter Sensitivity Analysis}

Based on the numerical model of defective lining, this paper calculates the crown and spandrel position of main lining and mainly discusses the influence of void range, lining thinning ratio, combined defects, load direction, and stratum stiffness on the mechanical behavior of the lining. The calculation conditions are shown in Table 2. In the table, load directions of $90^{\circ}, 45^{\circ}$, and $0^{\circ}$ represent vertical, oblique, and horizontal directions, respectively. The stratum stiffness is measured by the model test value and the recommended stratum resistance coefficient of grade III-V surrounding rock in tunnel code.

5.1. Voids. In terms of the calculation of vault crown voids and spandrel voids, 2 load directions and 4 kinds of stratum stiffness are considered. The void sizes are $0^{\circ}, 15^{\circ}, 30^{\circ}, 45^{\circ}, 60^{\circ}$, and $75^{\circ}$, respectively. Taking class III surrounding rock $(k=850 \mathrm{MPa} / \mathrm{m})$ as an example, the load-displacement curves of lining under different dimensions of vault crown voids and spandrel voids are shown in Figures 8 and 9, respectively. It can be seen from Figure 8 that the voids have little effect on the load-displacement response of lining when the size of vault is small $\left(\alpha \leq 15^{\circ}\right)$. When the size of voids reaches $30^{\circ}$ or more, the curvature of the rising section of the load-displacement curve of lining decreases obviously, the peak load decreases obviously, the curve drops suddenly after the peak load, and the lining shows obvious brittle failure characteristics. It can be seen that when the size of the void is larger $\left(\alpha>15^{\circ}\right)$, the voids obviously change the stiffness, bearing capacity, and deformation performance of the lining. The load-displacement curves of lining are similar under $45^{\circ}$ oblique and horizontal loads. Because the loading position is far away from the void position under horizontal loading, the bearing capacity of the lining under horizontal loading is obviously larger than that under $45^{\circ}$ oblique loading and is 
TABLe 2: Calculation conditions.

\begin{tabular}{lccccc}
\hline Calculation conditions & Defect position & Load direction & Void range & Thinning ratio & Stratum stiffness $(\mathrm{MPa} / \mathrm{m})$ \\
\hline $1 \sim 48(48)$ & Crown & $45^{\circ}, 0^{\circ}$ & $0^{\circ}, 15^{\circ}, 30^{\circ}, 45^{\circ}, 60^{\circ}, 75^{\circ}$ & - & $27.9,150,400,850$ \\
$49 \sim 92(44)$ & Spandrel & $90^{\circ}, 0^{\circ}$ & $0^{\circ}, 15^{\circ}, 30^{\circ}, 45^{\circ}, 60^{\circ}, 75^{\circ}$ & - & $27.9,150,400,850$ \\
$93 \sim 116(24)$ & Crown & $90^{\circ}, 45^{\circ}, 0^{\circ}$ & - & $0.25 \%, 50 \%$ & $27.9,150,400,850$ \\
$117 \sim 140(24)$ & Spandrel & $90^{\circ}, 45^{\circ}, 0^{\circ}$ & - & $0.25 \%, 50 \%$ & $27.9,150,400,850$ \\
$141 \sim 220(80)$ & Crown & $45^{\circ}, 0^{\circ}$ & $15^{\circ}, 30^{\circ}, 45^{\circ}, 60^{\circ}, 75^{\circ}$ & $25 \%, 50 \%$ & $27.9,150,400,850$ \\
$221 \sim 300(80)$ & Spandrel & $90^{\circ}, 0^{\circ}$ & $15^{\circ}, 30^{\circ}, 45^{\circ}, 60^{\circ}, 75^{\circ}$ & $25 \%, 50 \%$ & $27.9,150,400,850$ \\
\hline
\end{tabular}

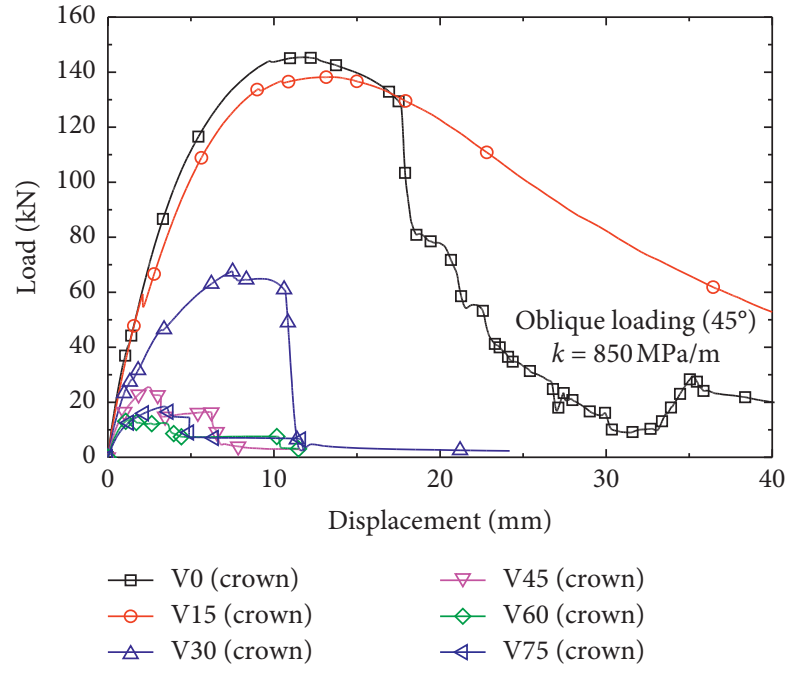

(a)

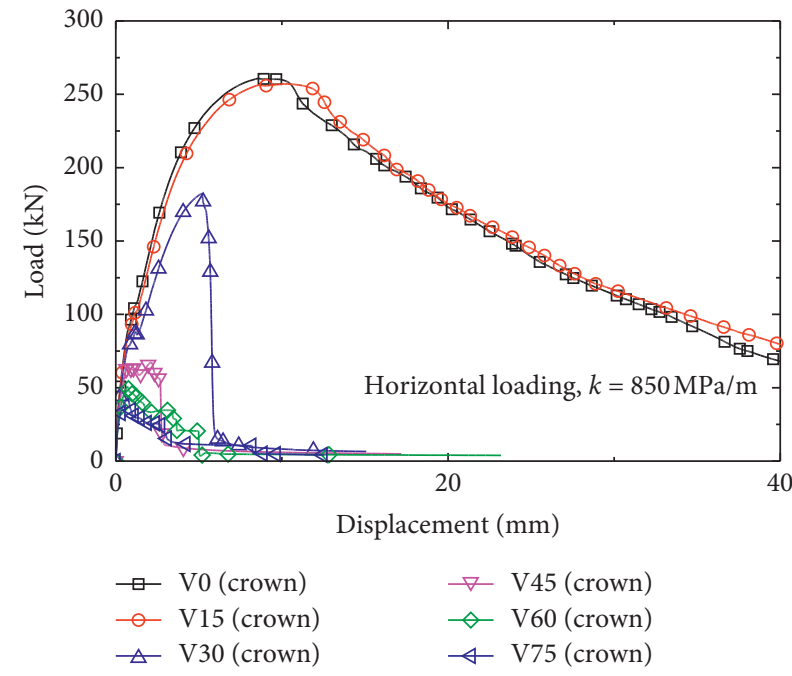

(b)

FIGURE 8: Load-displacement cure of the lining under crown voids. (a) $45^{\circ}$ oblique loading. (b) Horizontal loading.

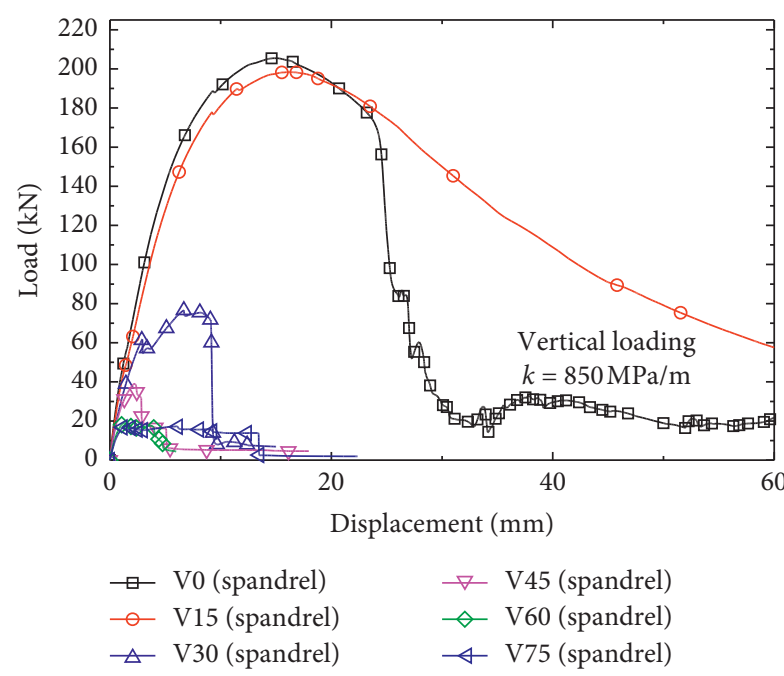

(a)

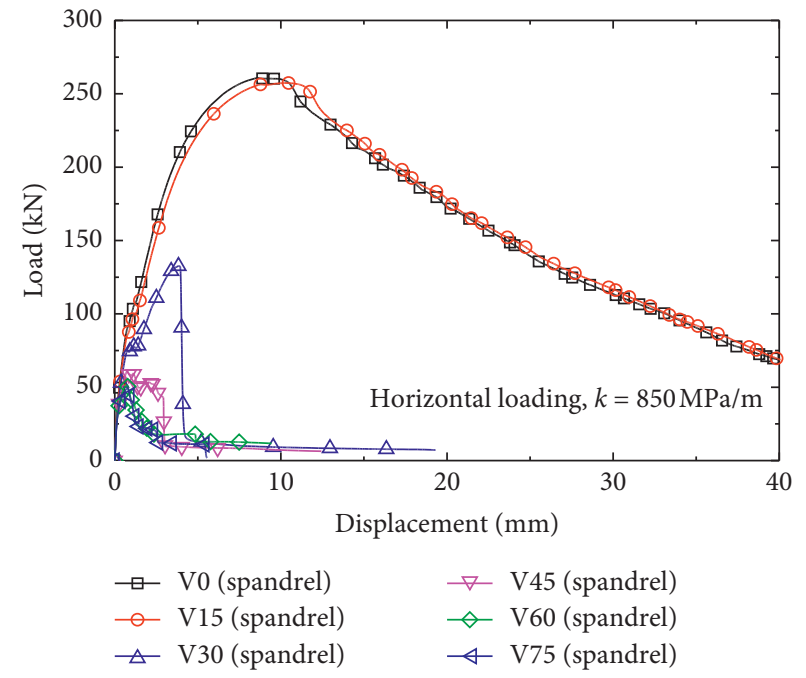

(b)

Figure 9: Load-displacement curve of the lining under spandrel voids. (a) Vertical loading. (b) Horizontal loading.

influenced less by the void size of the vault. Figure 9 shows that the law of load-displacement response and the influence of load direction on the bearing capacity of lining under the spandrel void are consistent with that of the vault crown void.

From the relationship curve between peak load and void size of lining (Figures 10 and 11), it can be seen that the bearing capacity of lining varies in three stages with the increase of void size under different stratum stiffness and loading modes. When the void range is less than $15^{\circ}$, the bearing capacity of lining decreases slowly; when the void range is between $15^{\circ}$ and $45^{\circ}$, the bearing capacity decreases rapidly; when the void range is greater than $45^{\circ}$, it decreases 


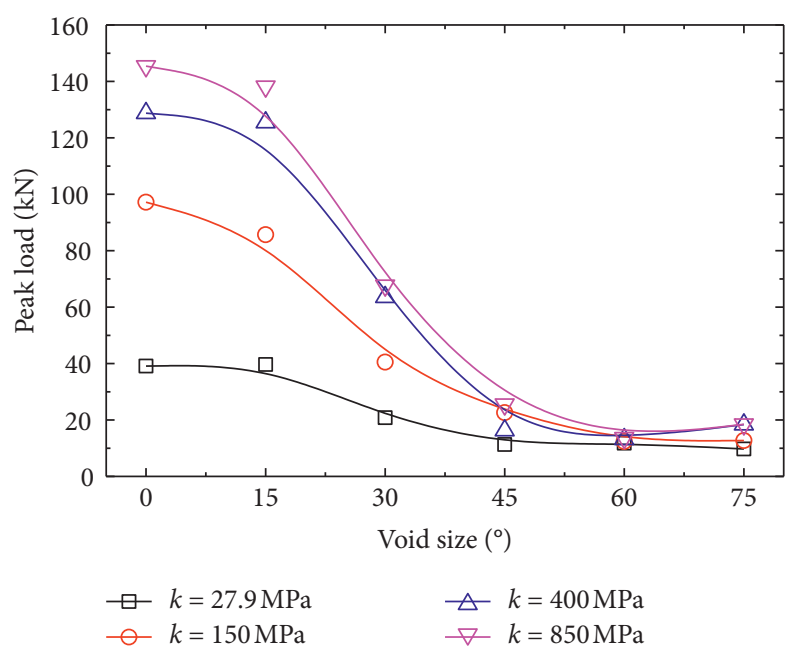

(a)

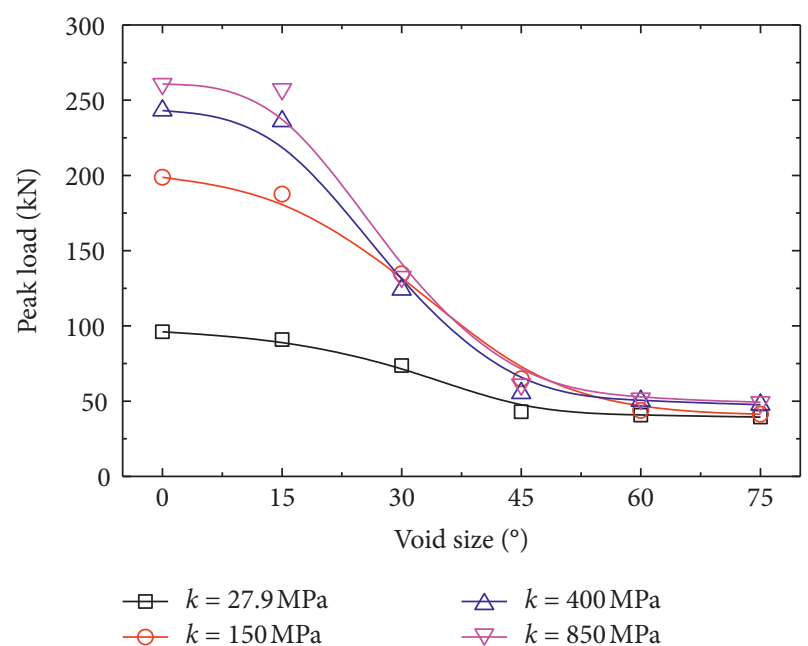

(b)

Figure 10: Peak load-crown void size relationship curve of the lining. (a) $45^{\circ}$ oblique loading. (b) Horizontal loading.

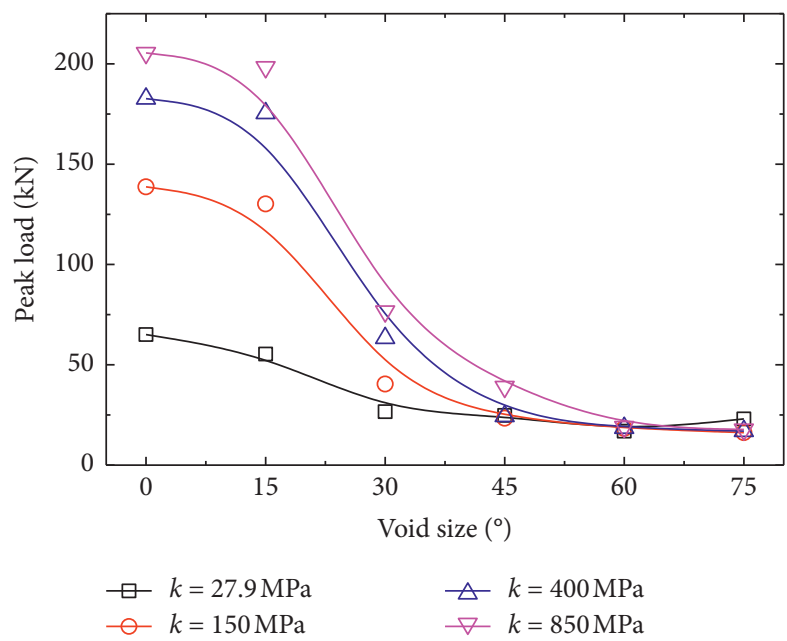

(a)

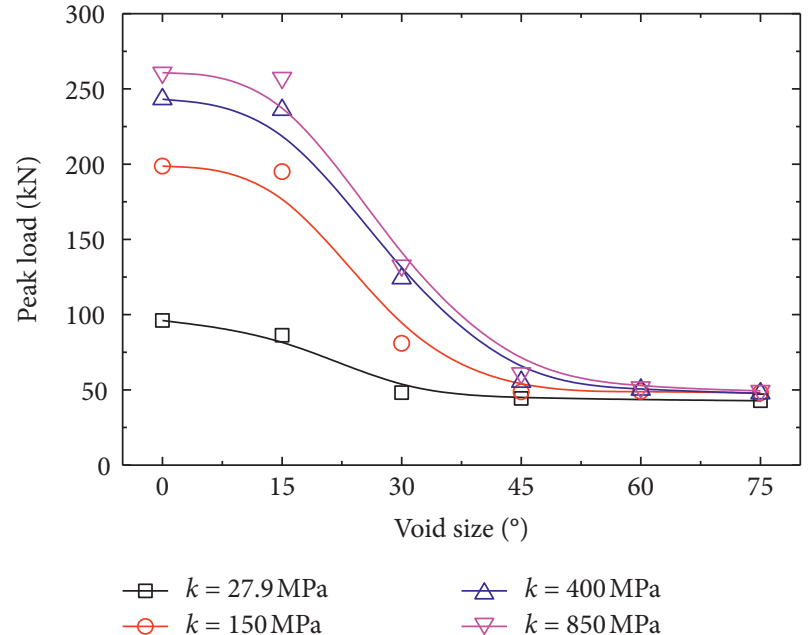

(b)

Figure 11: Peak load-spandrel void size relationship curve of the lining. (a) Vertical loading. (b) Horizontal loading.

slower. For example, when the stratum stiffness $k=850 \mathrm{MPa} / \mathrm{m}$, the bearing capacity of the three stages under oblique loading decreases by $7.19 \mathrm{kN}, 112.68 \mathrm{kN}$, and $7.07 \mathrm{kN}$, respectively, which decreases by $4.9 \%, 81.5 \%$, and $27.7 \%$. For the same stratum stiffness, the bearing capacity of the three stages under vertical loading decreases by $7.11 \mathrm{kN}$, $159.30 \mathrm{kN}$, and $21.23 \mathrm{kN}$, respectively, which decreases by $3.5 \%, 80.3 \%$, and $54.4 \%$. It can also be seen from the graph that the greater the stratum stiffness, the higher the bearing capacity of lining and the more obvious the three-stage characteristics of the bearing capacity and the void size curve. This shows that the better the surrounding rock, the greater the influence of voids on bearing capacity.

5.2. Insufficient Thickness of the Lining. In terms of the calculation of insufficient thickness of the lining at the vault crown and spandrel, vertical, oblique, and horizontal load directions are considered with the thinning ratio as $0 \%, 25 \%$, and $50 \%$, respectively. Similarly, the load-displacement curves of lining under different thinning ratios are shown in Figure 12, exemplified by class III surrounding rock $(k=850 \mathrm{MPa} / \mathrm{m})$. It can be seen from the figure that the effect of thinning on the load-displacement response of lining varies under different load modes. Generally speaking, the load exerted on the thinning part of the lining has a significant impact on its bearing capacity, on which the load exerted on other locations has a relatively small impact. With the increase of the thinning, the lining stiffness decreases, and the curve declines quicker after the lining reaches the peak load under the three load modes, which makes the lining more vulnerable to brittle failure.

The curve on the relationship of peak load-thinning ratio of lining (Figures 13(a) and 14(b)) shows that the bearing 

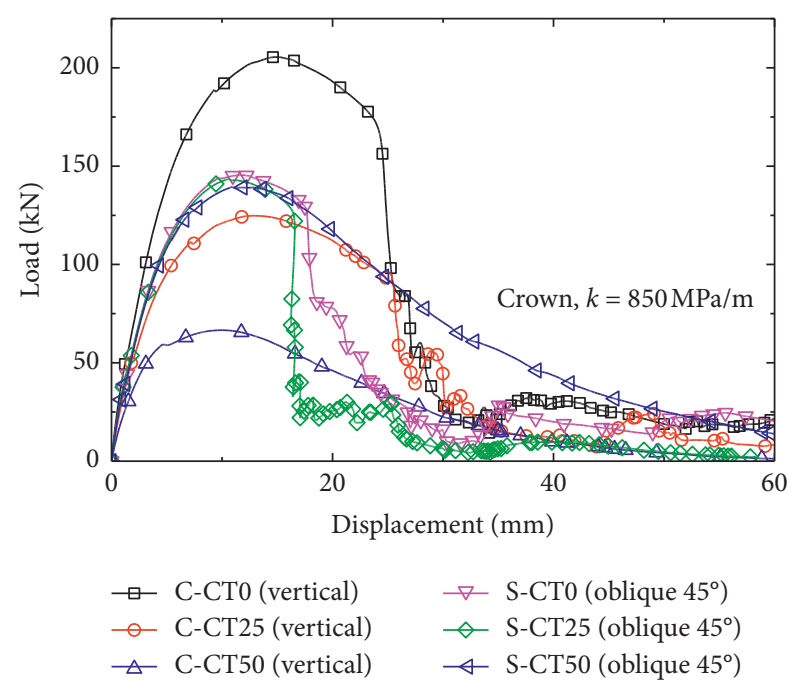

(a)
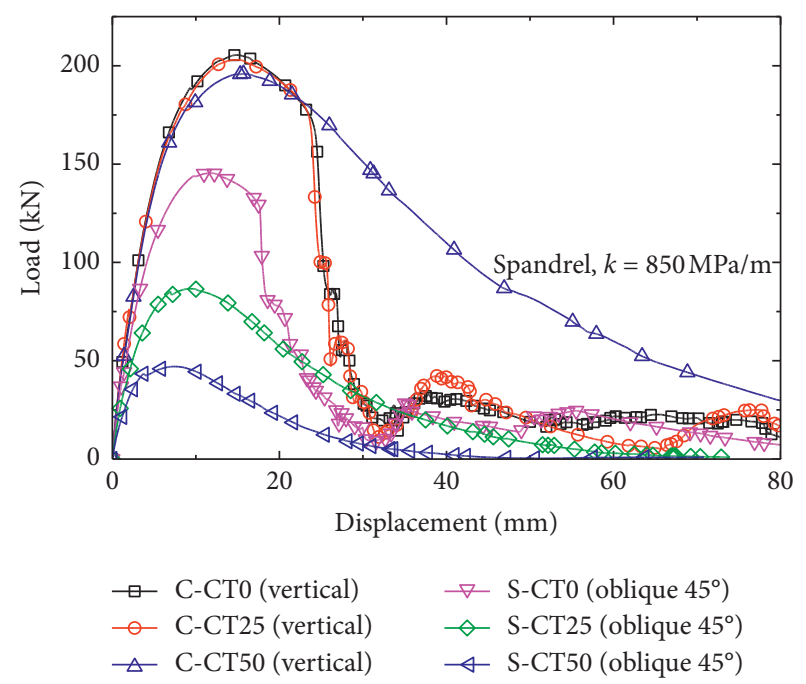

(b)

FIgURE 12: Load-displacement curve of thinned lining. (a) Thinning of lining at vault crown. (b) Thinning of lining at vault spandrel.

capacity of lining decreases linearly with the increase of thinning ratio at different stratum stiffness when the loading position falls in the thinning part of the lining. Taking stratum stiffness $k=150 \mathrm{MPa} / \mathrm{m}$ as an example, as the thinning ratio of the lining at vault crown increases from 0 to $50 \%$, the bearing capacity of lining decreases by $97.92 \mathrm{kN}$, namely, by $70.6 \%$ while as the thinning ratio of the lining at vault spandrel increases from 0 to $50 \%$, the bearing capacity of lining decreases by $62.48 \mathrm{kN}$, namely, by $64.2 \%$. Taking stratum stiffness $k=850 \mathrm{MPa} / \mathrm{m}$ as an example, as the thinning ratio of the lining at vault crown increases from 0 to $50 \%$, the bearing capacity of lining decreases by $138.87 \mathrm{kN}$, namely, by $67.6 \%$, while as the thinning ratio of the lining at vault spandrel increases from 0 to $50 \%$, the bearing capacity of lining decreases by $98.4 \mathrm{kN}$, namely, by $67.7 \%$. It can be seen that the greater the stratum stiffness, the faster the linear decrease of the bearing capacity of lining with thinning ratio, which indicates that the better the surrounding rock, the greater the influence of lining thinning on bearing capacity. From Figures 13(b), 13(c), 14(a), and 14(c), it can be concluded that the influence of other loading positions on the bearing capacity of lining is subtle except at the thinning point, and the farther away from the thinning point, the smaller the influence on the bearing capacity.

5.3. Combined Defects. Similarly, the load-displacement curves of the lining under typical defect combination are shown in Figure 15, exemplified by class III surrounding rock $(k=850 \mathrm{MPa} / \mathrm{m})$. The figure shows that the combined defects seriously weaken the bearing capacity and deformation performance of the lining and will accelerate the damage process of the lining. When the vault lining has a $30^{\circ}$ void and a $25 \%$ thinning, the bearing capacity of the lining under $45^{\circ}$ oblique load and horizontal load decreases by $54.8 \%$ and $32.9 \%$, respectively, and the corresponding displacement under peak load decreases by $33.3 \%$ and $44.3 \%$, respectively. When the crown void and the thinning ratio increase to $60^{\circ}$ and $50 \%$, respectively, the bearing capacity of the lining under the two loads decreases by $91.9 \%$ and $80.8 \%$, respectively, and the corresponding displacement decreases by $84.4 \%$ and $90.1 \%$ with basically lost bearing capacity and deformation capacity. Similarly, the effect of combined defects at vault spandrel on the mechanical properties of lining is similar to that of vault crown. When the spandrel lining has a $30^{\circ}$ void and a $25 \%$ thinning, the bearing capacity of the lining under vertical and horizontal loads decreases by $66.4 \%$ and $51.5 \%$, respectively, and the corresponding displacement under peak load decreases by $62.6 \%$ and $61.9 \%$, respectively. When the void and the thinning ratio increase to $60^{\circ}$ and $50 \%$, the bearing capacity of the lining under the two loads decreases by $92.2 \%$ and $80.8 \%$, respectively, and the corresponding displacement decreases by $88.7 \%$ and $90.8 \%$.

The three-dimensional curved surfaces of peak load of lining varying with combined defects under two kinds of stratum stiffness $(k=150 \mathrm{MPa} / \mathrm{m}$ and $850 \mathrm{MPa} / \mathrm{m})$ are shown in Figures 16 and 17. The figures show that under different defect locations and load directions, the influence of combined defects on the bearing capacity of lining is consistent, but the influence level is different. The peak load decreases in a "S" shape with the increase of the combined defect level, and the larger the stratum stiffness, the larger the decrease of the bearing capacity of the lining caused by the combined defect.

5.4. Analysis of the Loss Rate of Bearing Capacity of Lining Affected by Defects. The void behind the lining and the insufficient thickness of the lining seriously affect the bearing capacity of the lining. In order to quantitatively evaluate such an effect, the loss rate of bearing capacity $\xi$ is defined as

$$
\xi=1-\frac{P}{P_{0}},
$$

where $P$ is the bearing capacity of the lining in the presence of defects and $P_{0}$ is the bearing capacity of the lining in the absence of defects. 


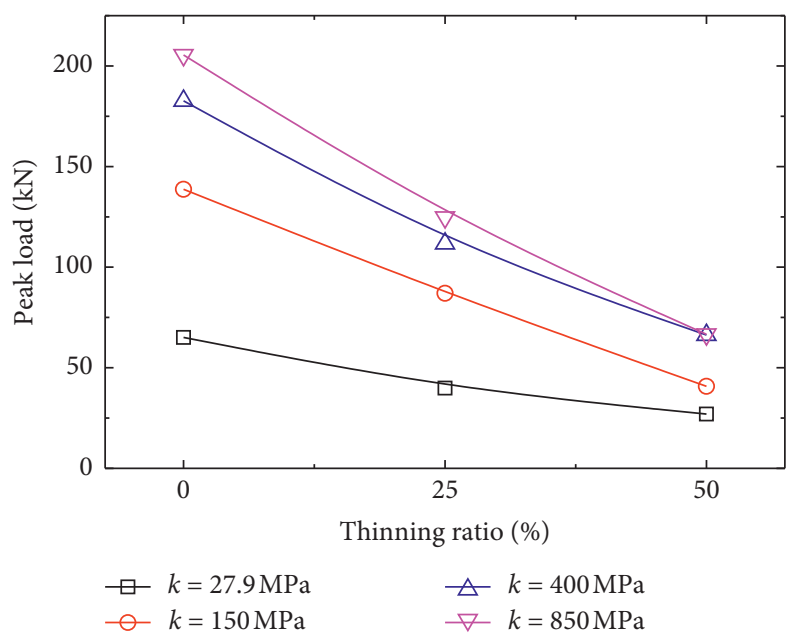

(a)

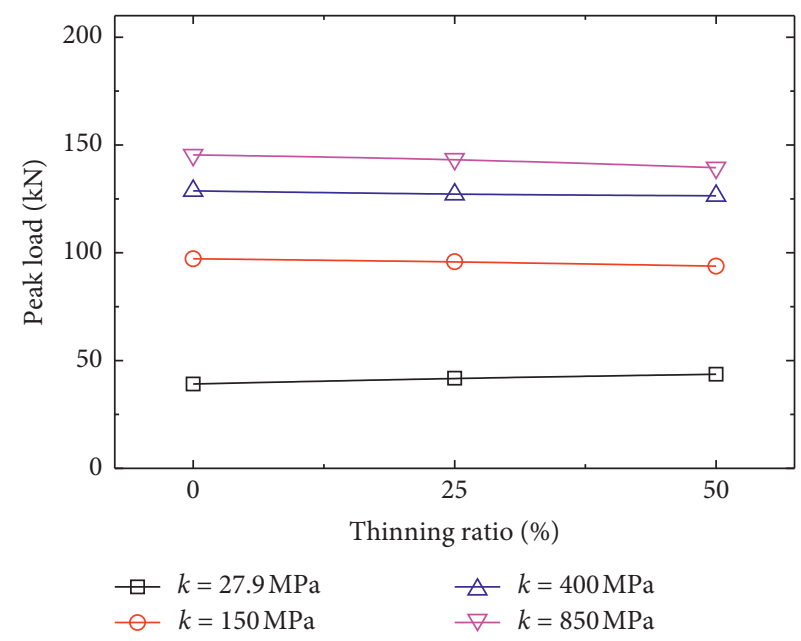

(b)

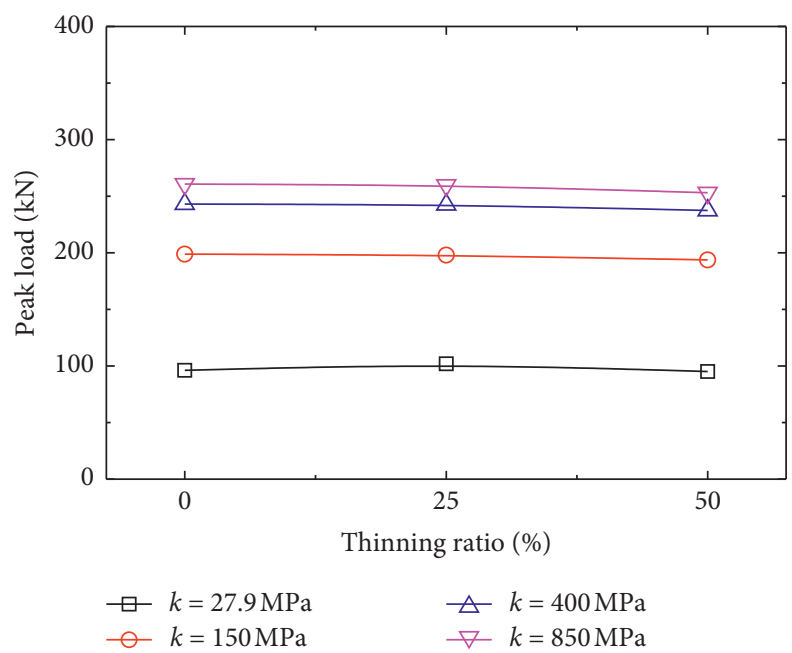

(c)

Figure 13: Variation curve of peak load-crown thinning ratio. (a) Vertical load. (b) $45^{\circ}$ oblique load. (c) Horizontal load.

For simplicity, the void size is dimensionless and $\eta$ is defined to represent the void size:

$$
\eta=\frac{L_{\mathrm{V}}}{\pi D}
$$

where $L_{\mathrm{V}}$ represents the vault length corresponding to the void range and $D$ represents the diameter of the lining vault.

From Figures 10 to 11 and the calculation results of bearing capacity loss rate under corresponding conditions, it is found that the bearing capacity loss rate of the lining has a good correlation with the logistic model with the increase of the void behind the lining. S-shaped growth curve (logistic model) can be used to describe the loss rate of bearing capacity of plain concrete lining under the influence of voids. The expression is as follows [28]:

$$
\xi=a-\frac{a}{1+(\eta / b)^{p}}
$$

where $a, b$, and $p$ are the fitting parameters and $p$ is the power $(p>0)$.
From Figures 13 to 14 and the calculation results of bearing capacity loss rate under corresponding working conditions, it can be seen that the influence of thinning ratio on the bearing capacity loss rate of the lining shows a linearly declining relationship, which can be described by a linear equation:

$$
\xi=c \delta,
$$

where $\delta$ is the thinning ratio and $c$ is the fitting parameter.

In addition, the influence of stratum stiffness on the loss rate of bearing capacity of defective lining is well correlated with the power function model. It can be described by the following expressions:

$$
\alpha=m k^{n},
$$

where $k$ represents stratum stiffness and $m$ and $n$ are fitting parameters.

By combining the above models properly and according to the results of Figures 16 and 17 and 


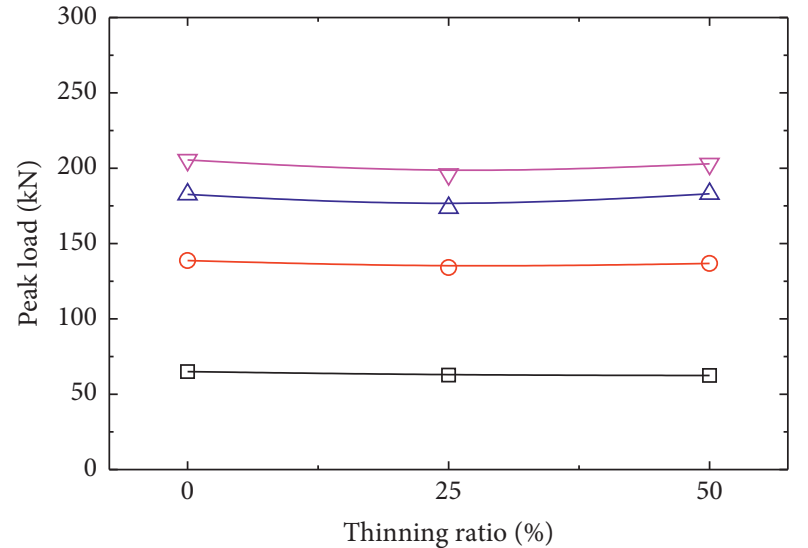

$\begin{array}{ll}\square-k=27.9 \mathrm{MPa} & \triangle k=400 \mathrm{MPa} \\ -k=150 \mathrm{MPa} & \nabla k=850 \mathrm{MPa}\end{array}$

(a)

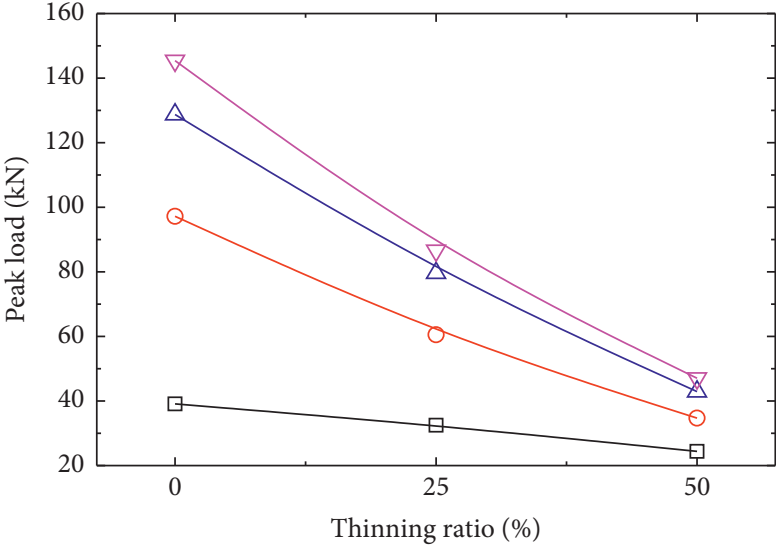

$\begin{array}{ll}\square-k=27.9 \mathrm{MPa} & \triangle k=400 \mathrm{MPa} \\ -k=150 \mathrm{MPa} & \nabla k=850 \mathrm{MPa}\end{array}$

(b)

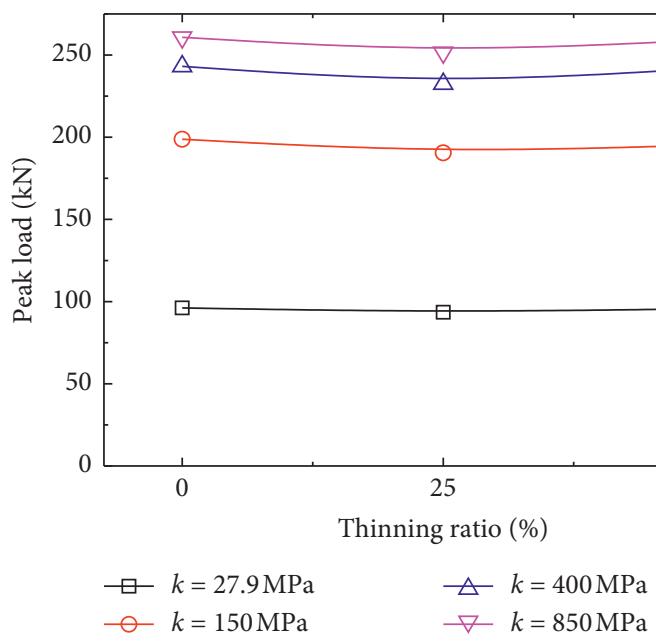

(c)

Figure 14: Variation curve of peak load-crown thinning ratio. (a) Vertical load. (b) $45^{\circ}$ oblique load. (c) Horizontal load.
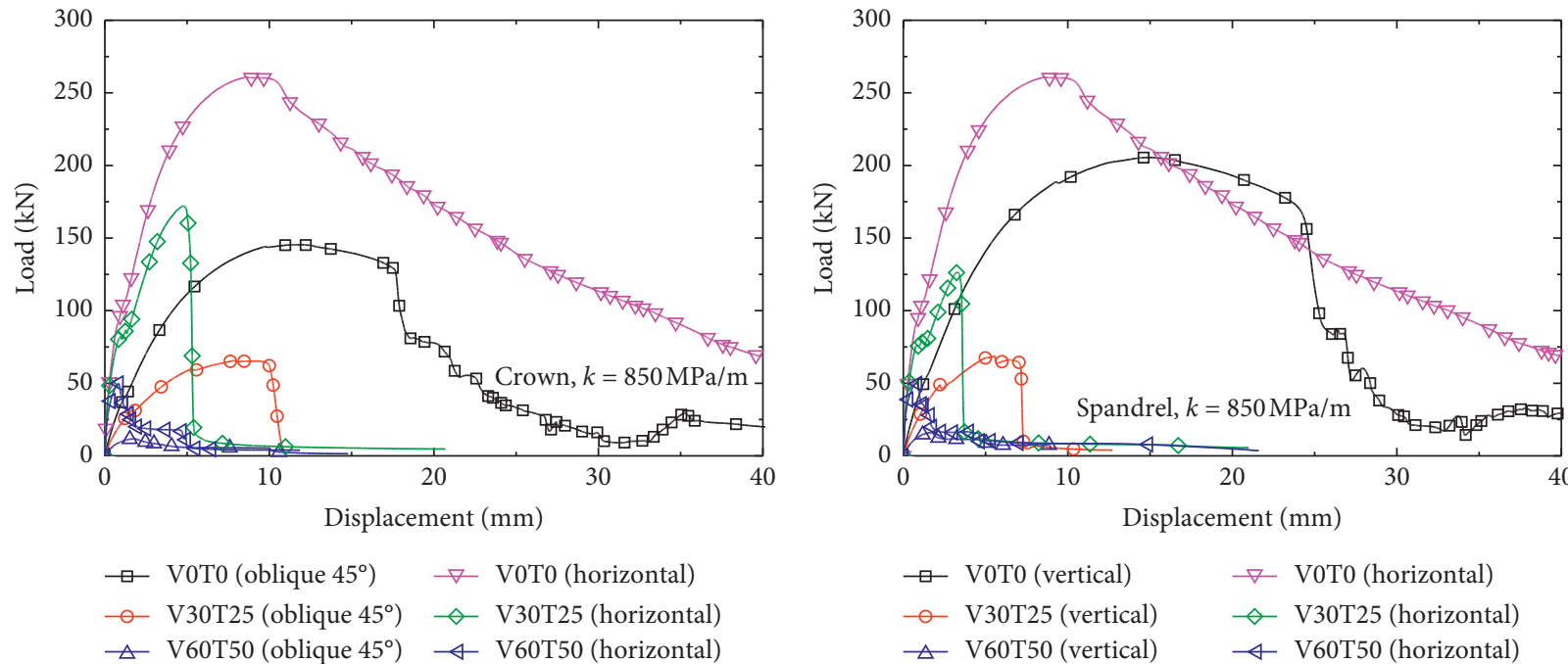

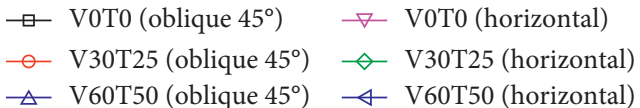

(a) (b)

Figure 15: Load-displacement curve of lining under combined defects. (a) Defects at vault crown. (b) Defects at vault spandrel. 


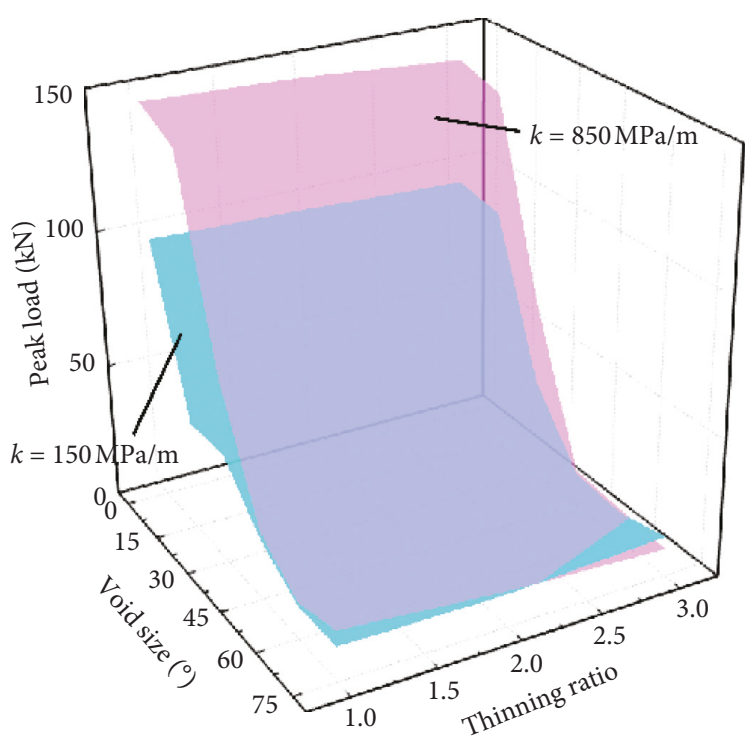

(a)

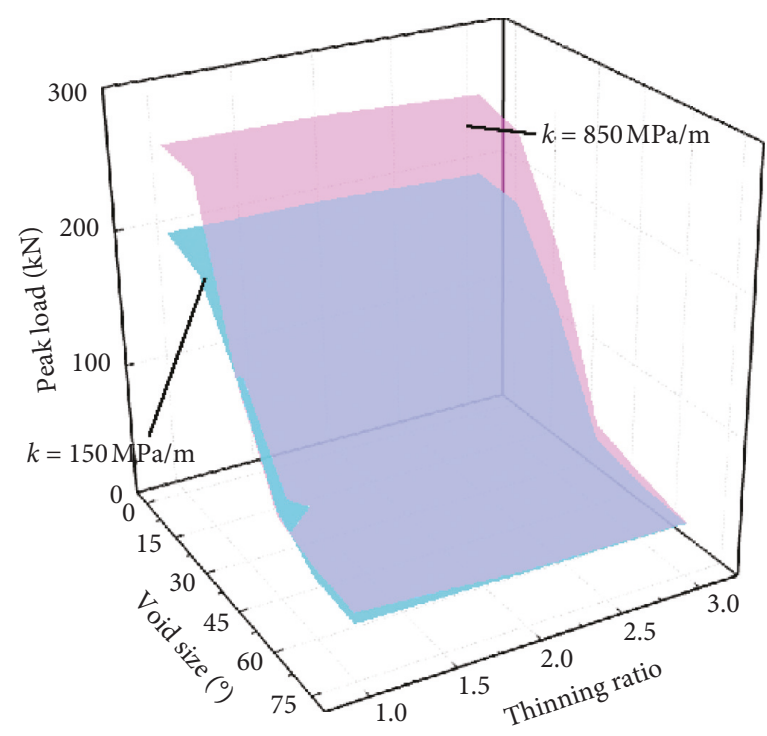

(b)

FiguRE 16: Three-dimensional curved surfaces of peak load and combined defects at vault crown. (a) $45^{\circ}$ oblique load. (b) Horizontal load.

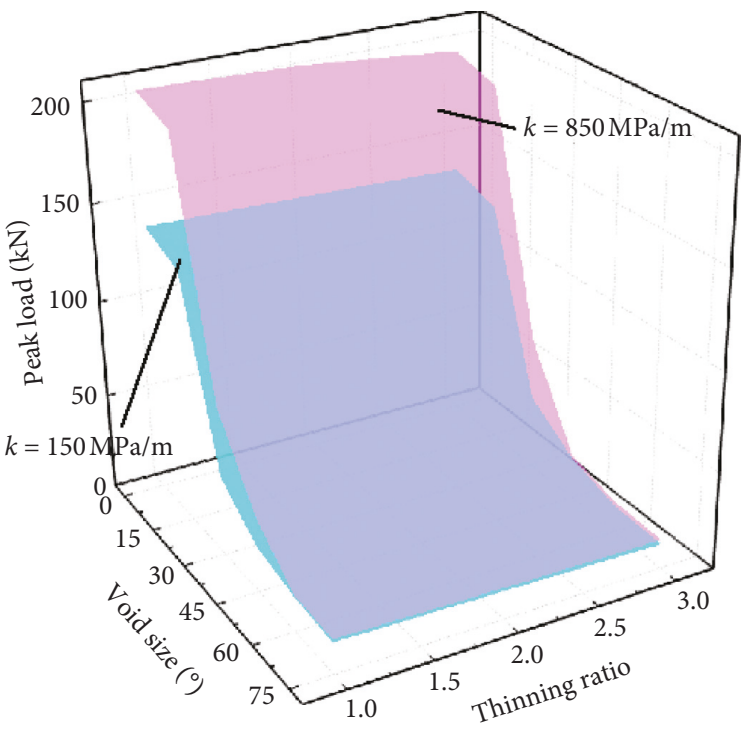

(a)

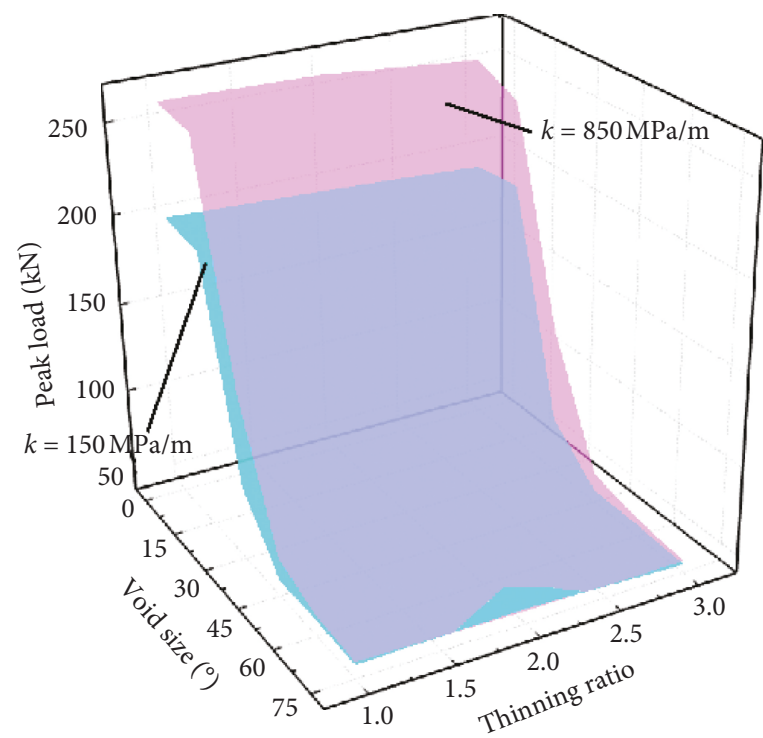

(b)

Figure 17: Three-dimensional curved surfaces of peak load and combined defects at vault spandrel. (a) Vertical load. (b) Horizontal load.

corresponding conditions, the equation of loss rate of bearing capacity of the plain concrete lining varying with void size, thinning ratio, and stratum stiffness can be established:

$$
\xi=\left\{\left[a-\frac{a}{1+(\eta / b)^{p}}\right]+(c \delta)\right\} m k^{n} .
$$

In order to verify the validity of the model, taking the combined defects at vault crown under oblique and horizontal loads and the combined defects at vault spandrel under vertical and horizontal loads as examples, the calculated loss rate of bearing capacity under the influence of combined defects is brought into equation (11). The LevenbergMarquardt method is used to carry out nonlinear regression, and the fitting parameters are obtained as shown in Table 3.

For the four cases in Table 3, the correlation coefficient obtained by fitting is between 0.974 and 0.986 , which shows high correlation of fitting results. It can be seen that the bearing capacity loss rate equation proposed in this paper can be used to evaluate the effect of voids and thinning on the bearing capacity of lining. 
TABLE 3: Fitting parameters of bearing capacity loss rate of lining under combined defects.

\begin{tabular}{lcccccccc}
\hline Defective part & Load direction & $a$ & $b$ & $p$ & $c$ & $m$ & $n$ & $R^{2}$ \\
\hline \multirow{2}{*}{ Crown } & Oblique $45^{\circ}$ & 0.1831 & 0.1509 & 5.0950 & 0.0094 & 3.4242 & 0.0577 & 0.986 \\
& Horizontal & 0.4054 & 0.1741 & 6.6478 & 0.0191 & 1.1493 & 0.0895 & 0.985 \\
\hline \multirow{2}{*}{ Spandrel } & Vertical & 1.6485 & 0.1339 & 4.7304 & 0.1369 & 0.3973 & 0.0490 & 0.985 \\
& Horizontal & 0.5973 & 0.1406 & 4.7159 & 0.0426 & 0.8021 & 0.0801 & 0.974 \\
\hline
\end{tabular}

\section{Conclusion}

In this paper, a $1 / 5$ scale lining model test and numerical calculation are carried out to study the mechanical behavior of plain concrete lining with voids, lining thinning, and combined defects. The main conclusions are as follows:

(1) Model test results show that the stiffness of lining decreases when there is a void behind the lining; the larger the void range is, the more easily the lining deforms. When a certain void size is reached, the surrounding rock has weak restraint function, and the bearing capacity and deformation performance of lining decrease significantly. The thinning of lining mainly affects its deformation performance, bearing capacity, and stiffness of thinned section. The load-displacement curve of the lining is sharp zigzag under the combined defect of void and thinning. The transition of elastic, elastic-plastic, and failure phases of the lining is no longer smooth, and the mechanical properties of the lining are obviously reduced.

(2) The numerical results show that under different stratum stiffness and loading modes, the bearing capacity of lining decreases from slow, rapid, to flat $S$-shaped curve with the increase of void range. The better the surrounding rock is, the greater the influence of voids on bearing capacity is.

(3) The bearing capacity of lining decreases linearly with the thinning ratio when the load is applied at the thinning point. The farther the distance from the thinning point, the smaller the influence on the bearing capacity. With the increase of thinning level, the decline speed of the curve increases when the lining reaches the peak load, and the lining is more vulnerable to brittle failure. Similarly, the better the quality of surrounding rock, the greater the influence of lining thinning on bearing capacity.

(4) Under different defect locations and load directions, the influence of combined defects on the bearing capacity of lining is consistent. The peak load of the lining decreases with the increase of the combined defect level, and the larger the stratum stiffness is, the larger the decrease of the bearing capacity of the lining caused by the combined defect.

(5) On the basis of model test and numerical calculation results, the bearing capacity loss rate equation of plain concrete lining considering the conditions of lining vault, lining thinning, and surrounding rock is established, which provides a theoretical basis for quantitative evaluation of the influence of existing defects on the bearing capacity of lining.

\section{Data Availability}

The data used to support the findings of this study are available from the corresponding author upon request.

\section{Conflicts of Interest}

The authors declare that there are no conflicts of interest regarding the publication of this paper.

\section{Acknowledgments}

This research was financially supported by the Science and Technology Project by Yunnan Transportation Department (Yunjiaoke 2016(A)01 and Yunjiaoke 2017(A)04) and National Natural Science Foundation of China (51768028).

\section{References}

[1] H. Wang, H. Huang, Y. Feng, and D. Zhang, "Characterization of crack and leakage defects of concrete linings of road tunnels in China," Asce-Asme Journal of Risk and Uncertainty in Engineering Systems, Part A: Civil Engineering, vol. 4, no. 4, Article ID 04018041, 14 pages, 2018.

[2] J. M. Feng, W. G. Qiu, and M. Q. Li, "The durability measures of the lining of newly built tunnels from lining disease of the existing tunnels," Advanced Materials Research, vol. 250-253, pp. 2626-2631, 2011.

[3] D. P. Zhao, X. R. Tan, and L. L. Jia, "Study on investigation and analysis of existing railway tunnel diseases," Applied Mechanics and Materials, vol. 580-583, pp. 1218-1222, 2014.

[4] W. Wang, S. C. Liao, P. Ding, and D. Z. Chen, "Analysis of tunnel defect characteristic caused by cavities behind lining," Advanced Materials Research, vol. 261-263, pp. 1265-1269, 2011.

[5] F. Huang, H. Zhu, Q. Xu, Y. Cai, and X. Zhuang, "The effect of weak interlayer on the failure pattern of rock mass around tunnel-scaled model tests and numerical analysis," Tunnelling and Underground Space Technology, vol. 35, no. 4, pp. 207218, 2013.

[6] F. Sandrone and V. Labiouse, "Identification and analysis of Swiss national road tunnels pathologies," Tunnelling and Underground Space Technology, vol. 26, no. 2, pp. 374-390, 2011.

[7] C. Leung and M. A. Meguid, "An experimental study of the effect of local contact loss on the earth pressure distribution on existing tunnel linings," Tunnelling and Underground Space Technology, vol. 26, no. 1, pp. 139-145, 2011.

[8] N. Yasuda, K. Tsukada, and T. Asakura, "Elastic solutions for circular tunnel with void behind lining," Tunnelling and Underground Space Technology, vol. 70, pp. 274-285, 2017.

[9] J. Wang, H. Huang, X. Xie, and A. Bobet, "Void-induced liner deformation and stress redistribution," Tunnelling and Underground Space Technology, vol. 40, pp. 263-276, 2014. 
[10] D. L. Zhang, S. L. Zhang, Q. Fang, and C. Fengbin, "Study of contact state behind tunnel lining in process of railway operation and its analysis," Chinese Journal of Rock Mechanics And Engineering, vol. 32, no. 2, pp. 217-224, 2013.

[11] M. A. Meguid and H. K. Dang, "The effect of erosion voids on existing tunnel linings," Tunnelling and Underground Space Technology, vol. 24, no. 3, pp. 278-286, 2009.

[12] C. L. Xin, Z. Z. Wang, and B. Gao, "Shaking table tests on seismic response and damage mode of tunnel linings in diverse tunnel-void interaction states," Tunnelling and Underground Space Technology, vol. 77, pp. 295-304, 2018.

[13] H. Mashimo, "State of the road tunnel safety technology in Japan," Tunnelling and Underground Space Technology, vol. 17, no. 2, pp. 145-152, 2002.

[14] B. Wang, T. B. Li, C. He, and J. She, "Model test of effect of lining thinning on tunnel structure bearing capacity," Journal of the China Railway Science, vol. 35, no. 2, pp. 106-114, 2013.

[15] Z. D. Ding, B. Zhang, X. Q. Li, J. Huang, and L. M. Peng, "Shaking table tests for investigating the effect of void behind lining on the seismic responses of a tunnel," Journal of Vibration and Shock, vol. 37, no. 14, pp. 156-161, 2018.

[16] C. Molins and O. Arnau, "Experimental and analytical study of the structural response of segmental tunnel linings based on an in situ loading test: part 1: test configuration and execution," Tunnelling and Underground Space Technology, vol. 26, no. 6, pp. 764-777, 2011.

[17] B. Min, X. Zhang, C. Zhang, Y. Gong, and T. Yuan, "Mechanical behavior of double-arch tunnels under the effect of voids on the top of the middle wall," Symmetry, vol. 10, no. 12, p. 703, 2018.

[18] Z. Ding, X. Ji, X. Li, Z. Ren, and S. Zhang, "Influence of symmetric and asymmetric voids on mechanical behaviors of tunnel linings: model tests and numerical simulations," Symmetry, vol. 11, no. 6, p. 802, 2019.

[19] N. Okano, "Development of a testing machine with a large tunnel lining model," Railway Technology Avalanche, vol. 19, p. 110, 2007.

[20] K. Yashiro, R. Hirata, N. Okano, and Y. Kojima, "Study on deformation and failure behavior of mountain tunnel linings which consist of various materials," Journal of Japan Society of Civil Engineers, Ser. F1 (Tunnel Engineering), vol. 71, no. 2, pp. 78-94, 2015.

[21] X. Huang, Y. Zhu, Z. Zhang, Y. Zhu, S. Wang, and Q. Zhuang, "Mechanical behaviour of segmental lining of a sub-rectangular shield tunnel under self-weight," Tunnelling and Underground Space Technology, vol. 74, pp. 131-144, 2018.

[22] W. He, Z. Wu, Y. Kojima, and T. Asakura, "Failure mechanism of deformed concrete tunnels subject to diagonally concentrated loads," Computer-Aided Civil and Infrastructure Engineering, vol. 24, no. 6, pp. 416-431, 2009.

[23] J. Lee and G. L. Fenves, "Plastic-damage model for cyclic loading of concrete structures," Journal of Engineering $\mathrm{Me}$ chanics, vol. 124, no. 8, pp. 892-900, 1998.

[24] X. Chen, L. Xu, D. Shi, Y. Chen, W. Zhou, and Q. Wang, "Experimental study on cyclic tensile behaviour of concrete under various strain rates," Magazine of Concrete Research, vol. 70, no. 2, pp. 55-70, 2017.

[25] B. Fib, Model Code for Concrete Structures 2010, Ernst and Sohn GmbH and Co. KG, pp. 190-350, Berlin Germany, 2013.

[26] J. A. Oller, Continuous Damage Model for Frictional Materials, Technical University of Catalonia, Barcelona, Spain, 1988.

[27] T. Yu, J. G. Teng, Y. L. Wong, and S. L. Dong, "Finite element modeling of confined concrete-II: plastic-damage model," Engineering Structures, vol. 32, no. 3, pp. 680-691, 2010.
[28] T. Yang, G. W. Li, and W. Q. Yang, "Settlement prediction of stage construction embankment on soft ground based on the hyperbola method," Rock and Soil Mechanics, vol. 25, pp. 1551-1554, 2004. 


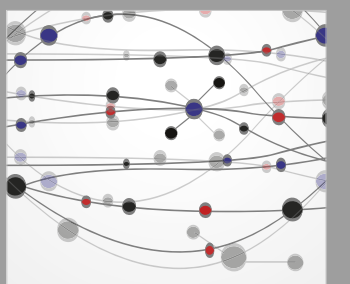

The Scientific World Journal
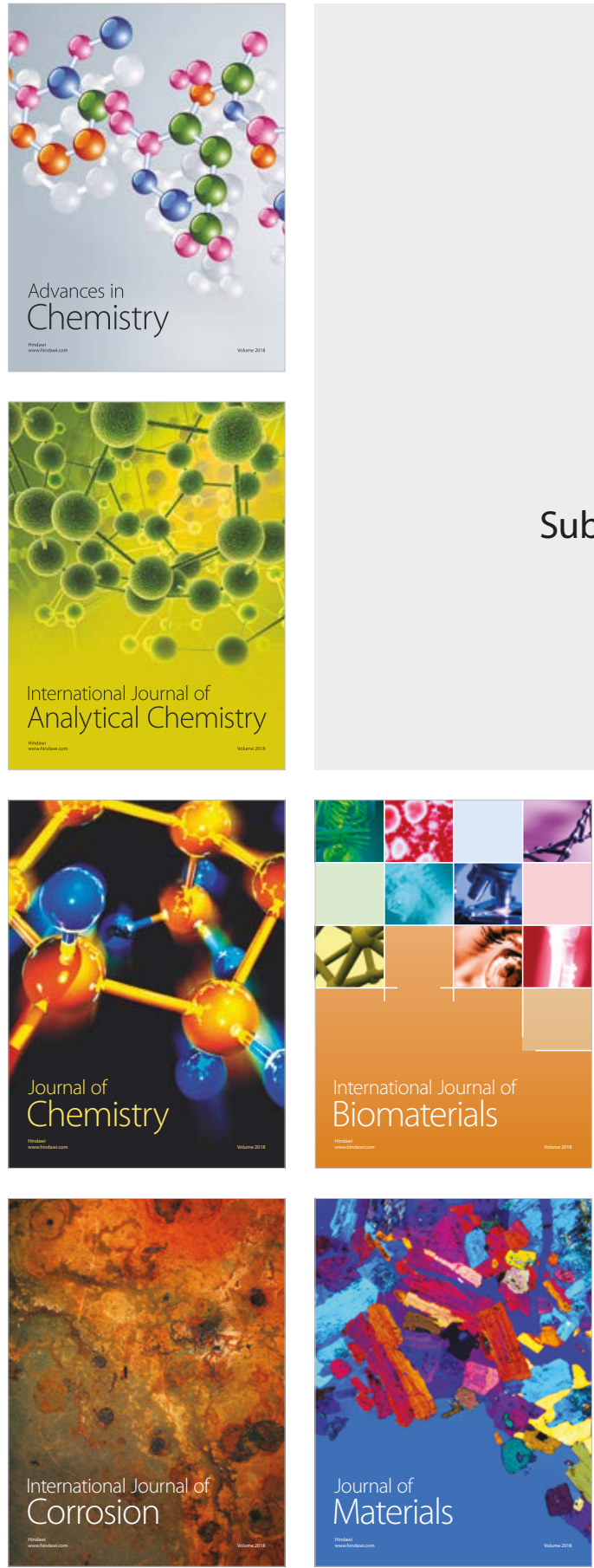

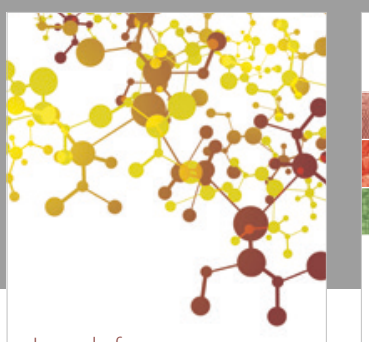

Journal of

Applied Chemistry
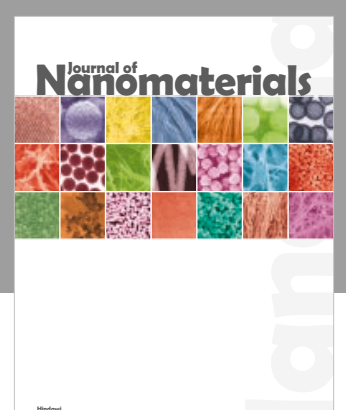

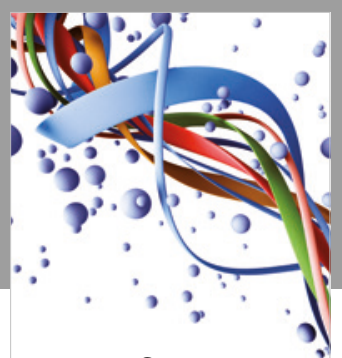

Scientifica

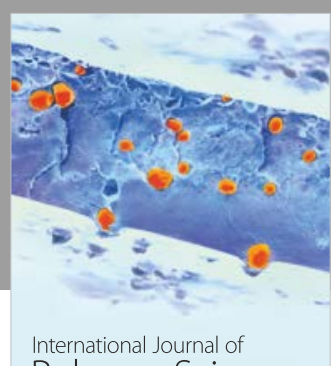

Polymer Science

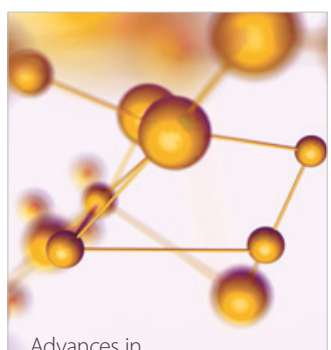

Physical Chemistry
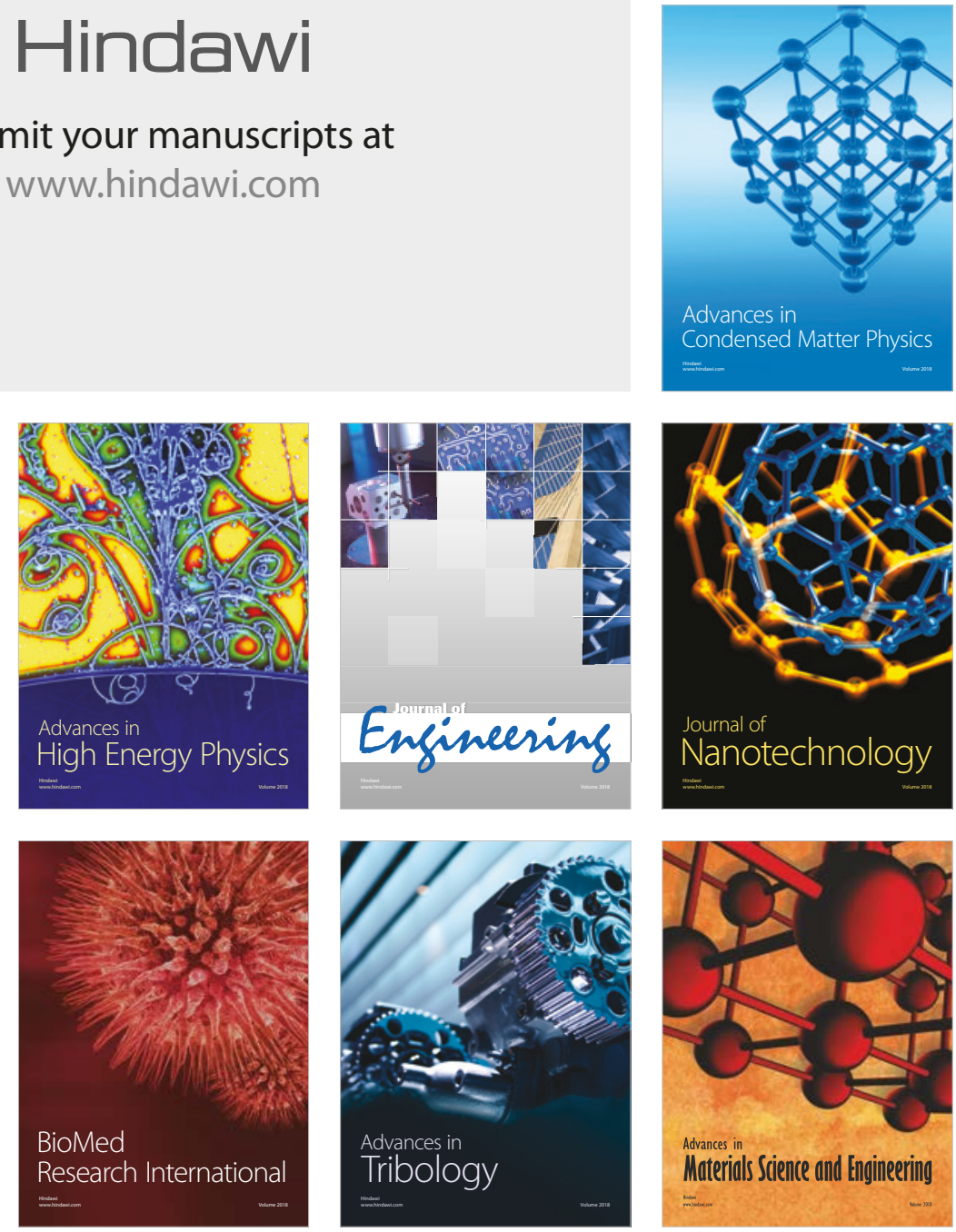